\title{
A Decoupling Control Algorithm for Unwinding Tension System Based on Active Disturbance Rejection Control
}

\author{
Shanhui Liu, ${ }^{1}$ Xuesong Mei, ${ }^{1,2}$ Fanfeng Kong, ${ }^{1}$ and Kui He \\ ${ }^{1}$ School of Mechanical Engineering, Xi'an Jiaotong University, No. 28, Xianning West Road, Xi'an, Shaanxi 710049, China \\ ${ }^{2}$ State Key Laboratory for Manufacturing Systems Engineering, Xian Jiaotong University, No. 28, Xianning West Road, Xian, \\ Shaanxi 710049, China
}

Correspondence should be addressed to Xuesong Mei; xsmei@mail.xjtu.edu.cn

Received 8 May 2013; Revised 18 September 2013; Accepted 25 September 2013

Academic Editor: Michael A. Sek

Copyright (C) 2013 Shanhui Liu et al. This is an open access article distributed under the Creative Commons Attribution License, which permits unrestricted use, distribution, and reproduction in any medium, provided the original work is properly cited.

\begin{abstract}
This paper presents a new control methodology based on active disturbance rejection control (ADRC) for designing the tension decoupling controller of the unwinding system in a gravure printing machine. The dynamic coupling can be actively estimated and compensated in real time, which makes feedback control an ideal approach to designing the decoupling controller of the unwinding system. This feature is unique to ADRC. In this study, a nonlinear mathematical model is established according to the working principle of the unwinding system. A decoupling model is also constructed to determine the order and decoupling plant of the unwinding system. Based on the order and decoupling plant, an ADRC decoupling control methodology is designed to enhance the tension stability in the unwinding system. The effectiveness and capability of the proposed methodology are verified through simulation and experiments. The results show that the proposed strategy not only realises a decoupling control for the unwinding system but also has an effective antidisturbance capability and is robust.
\end{abstract}

\section{Introduction}

Tension control stability is essential to the printing process of the gravure printing machines because the fluctuation and variation of tension have great influence on the precision of the printing register. The unwinding system is vital for generating web tension in the tension control system of the machine. In the process of unwinding, the diameter and rotational inertia of the unwinding roller are time-variant, which creates an indeterminate tension control system that is nonlinear and strong-coupling. Hence, accurate tension control is essential for ensuring adequate printing performance.

Presently, the control synthesis methodology based on the proportional-integral-derivative (PID) algorithm is still the most common control strategy for the tension control system of the gravure printing machines. However, with the development of high-speed and high-precision printing technologies, a control strategy based solely on PID is insufficient for satisfying control requirements. Many researchers have focused their efforts on improving the traditional PID strategy [1-6]. With the development of modern control theories, a number of modern control methods have been applied to web tension control. Chung et al. [7] applied fuzzy logic control to tension control. Wang et al. [8] achieved decoupling control between tension and speed using neural networks. Abjadi et al. [9] designed a decoupling controller based on nonlinear slidingmode control for the tension control system. Pagilla et al. $[10,11]$ proposed fully decentralized state feedback controller and verified the controller by experimental results. A decentralized adaptive controller with model based feedforward was developed and experimentally verified in [12]. As the web processing plants are known as highly resonant systems with strong coupling between the variables to control, several improvements of multivariable controllers based on robust control have been introduced to address the resonant effects and tension control while maintaining performance [13-20]. Although most of these methods resulted in acceptable control performance, they relied too heavily on the system model. However, in industrial practice, it is very difficult to establish a fully accurate mathematical model. Therefore, it was necessary to find a solution using a small amount of model information that could effectively address the nonlinear, timevarying, strong coupling, and uncertain nature of web tension control. One ideal candidate is the ADRC. The 


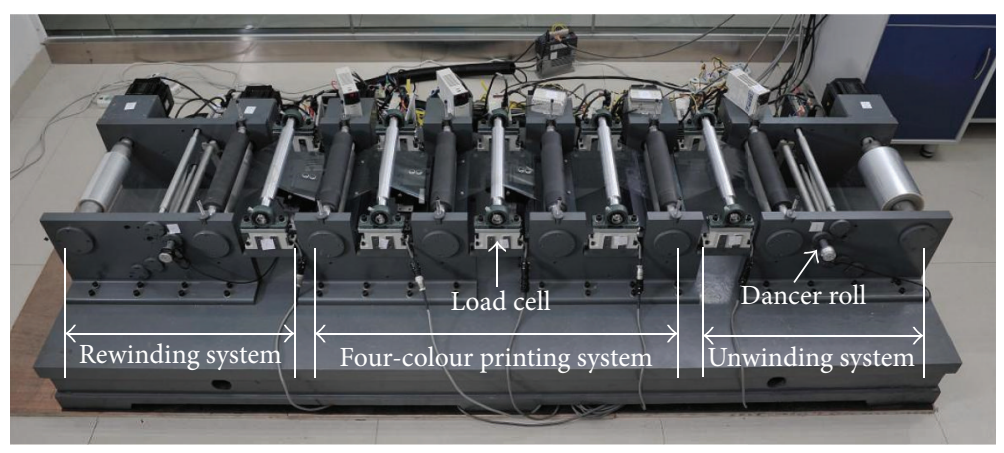

FIGURE 1: Experimental setup for the four-colour gravure printing machine.

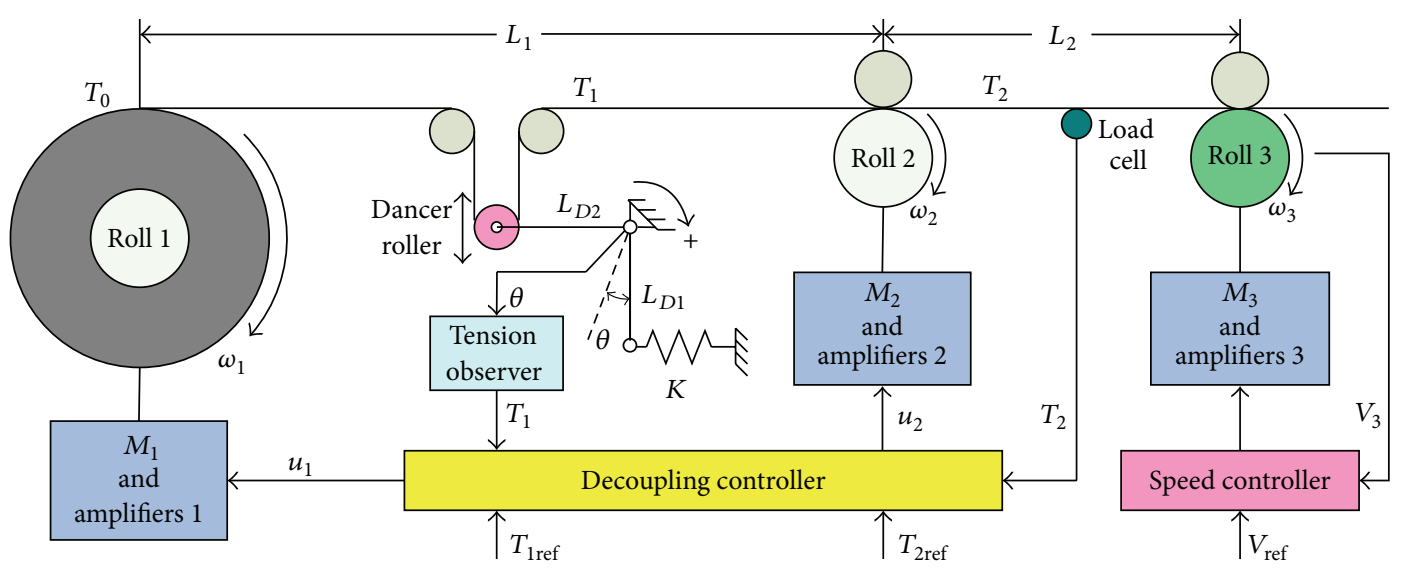

FIGURE 2: Schematic diagram of the unwinding system.

essence of ADRC is that the internal dynamics and external disturbances can be estimated and compensated in real time [21-24]. Due to its strong robustness and antidisturbance capability, ADRC has been successfully applied in many fields [25-28]. An initial evaluation of the application of ADRC for the regulation of web tension was performed with a linear transfer function model of the tension loop [29]. ADRC was then applied to design control methodologies for a truly nonlinear model of the tension dynamics in [30, 31]; acceptable performance was observed. Few researchers have addressed the design of tension decoupling control methodology based on ADRC, particularly, with regard to the unwinding system for gravure printing machines.

The objective of this research is to design a tension decoupling control methodology based on ADRC for the unwinding system in gravure printing machines. First, a nonlinear model is established based on the working principle of unwinding system. Next, a decoupling model is constructed in detail and an ADRC decoupling controller is designed to enhance the tension stability of the unwinding system. Last, to test the effectiveness of the ADRC controller, simulations and experiments with PID and ADRC controllers are carried out.

\section{Mathematical Modeling}

2.1. Experimental Setup. Figure 1 shows the experimental setup for a four-colour gravure printing machine that consists of an unwinding system, a four-colour printing system, and a rewinding system. All of the driving shafts are driven by Mitsubishi servo motors. The unwinding and rewinding rollers are driven by HF-SP102, and the other rollers are driven by HF-SE52JW1-S100. Tension signals are measured by passive dancer rolls with tension observer and Mitsubishi tension load cells (LX-030TD). The entire system is controlled by a multiaxis controller (Googoltech T8VME). The experimental web material is biaxially oriented polypropylene (BOPP).

The schematic diagram of the unwinding system in the experimental setup is presented in Figure 2. To achieve constant tension control, the unwinding system consists primarily of an unwinding component driven by $M_{1}$ and a traction component driven by $M_{2}$. A passive dancer roll is used in the unwinding component to reduce tension fluctuations and simultaneously measure the tension signal $T_{1}(t)$ by the position $\theta$ and tension observer [32]. To simplify the mathematical model, the upstream and downstream tensions of the dancer roller and the idle rollers are considered equal. In the traction component, the value of $T_{2}(t)$ is measured by the tension load cell. $M_{3}$ is the first printing motor whose main task is to maintain a constant speed.

2.2. System Model. The standard model of the relationship between tension and velocity has been presented in $[4,13,32-$ 34]. The model is constructed from equations that describe the web tension behaviour of two consecutive rolls and 


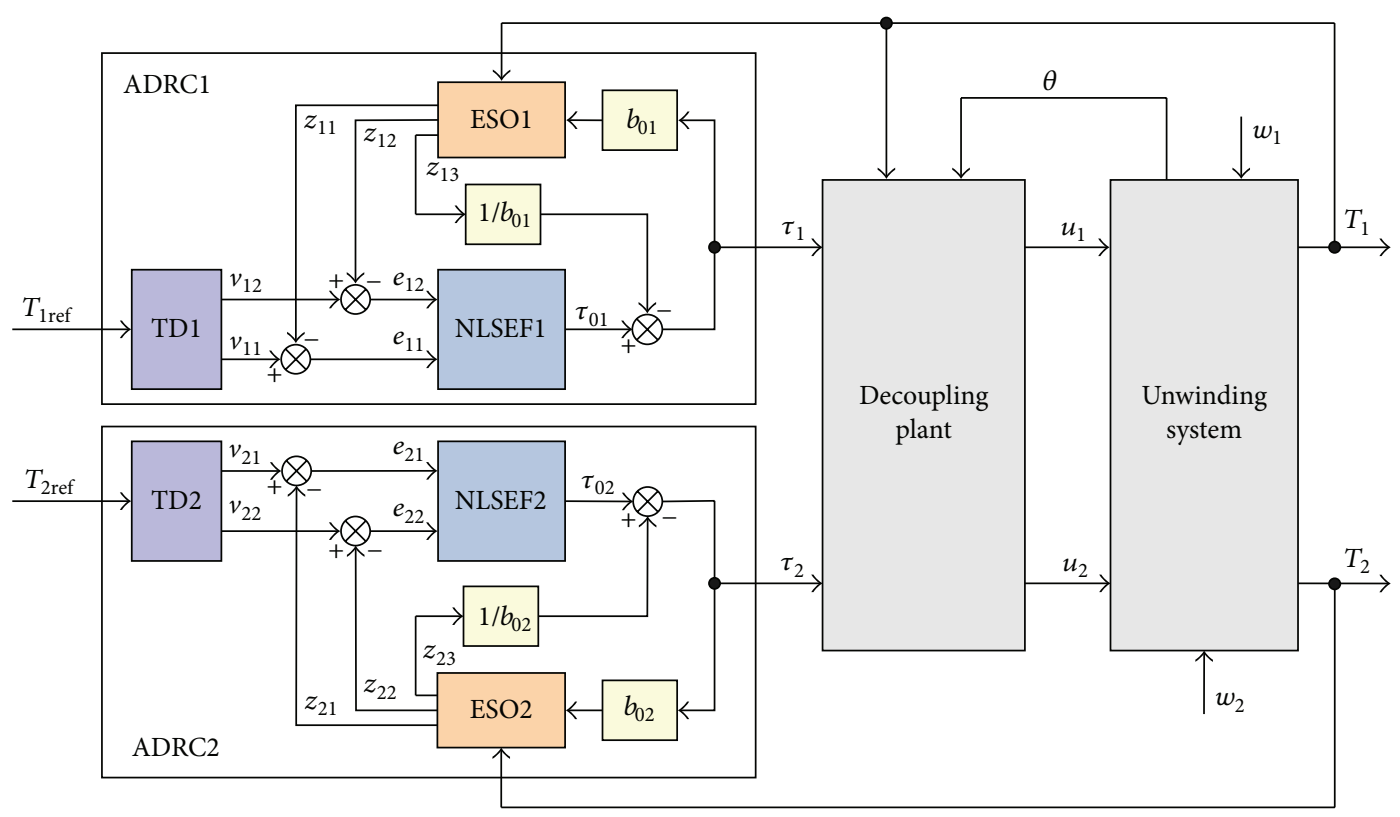

FIGURE 3: Structure of the ADRC decoupling control methodology.

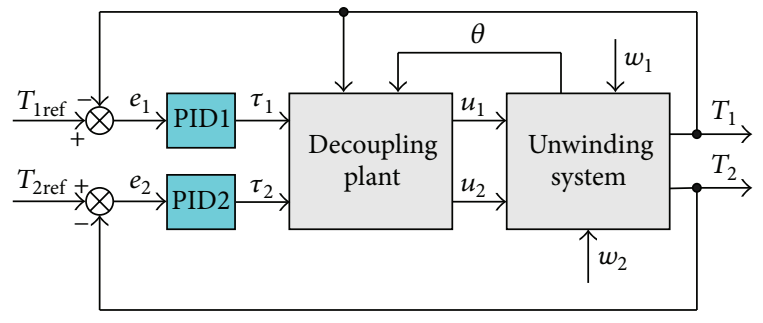

FIGURE 4: Structure of the PID control methodology.

the velocity of each roll. The relationship between the tension and velocity of the unwinding system can be expressed as

$$
\begin{aligned}
L_{i}(t) & \frac{d T_{i}(t)}{d t} \\
= & V_{i}(t) T_{i-1}(t)-V_{i+1}(t) T_{i}(t)+A E\left(V_{i+1}(t)-V_{i}(t)\right) \\
& +\left(A E-T_{i}(t)\right) \frac{d L_{i}(t)}{d t} \quad i=1,2 .
\end{aligned}
$$

Equation (1) is a nonlinear tension model that considers variation in web length within a span. As shown in Figure 2, $L_{2}(t)$ is constant for $L_{2}$. Substituting $V(t)=R(t) \omega(t)$ into (1), we can obtain

$$
\begin{gathered}
L_{1}(t) \dot{T}_{1}(t)=\left(T_{0}-A E\right) R_{1}(t) \omega_{1}(t) \\
+\left(A E-T_{1}(t)\right) R_{2} \omega_{2}(t) \\
+\left(A E-T_{1}(t)\right) \dot{L}_{1}(t), \\
L_{2} \dot{T}_{2}(t)=\left(T_{1}(t)-A E\right) R_{2} \omega_{2}(t)+\left(A E-T_{2}(t)\right) R_{3} \omega_{3} .
\end{gathered}
$$

Assuming that the web does not completely slide on the roll and that the web velocity is equal to roll linear velocity and by applying Newton's law to the rotational movement, (3) can be expressed as

$$
\begin{aligned}
\frac{d}{d t}\left(J_{i}(t) \omega_{i}(t)\right)= & \left(T_{i}(t)-T_{i-1}(t)\right) R_{i}(t) \\
& +C_{i} u_{i}(t)-f \omega_{i}(t), \quad i=1,2 .
\end{aligned}
$$

Because $R_{1}(t)$ and $J_{1}(t)$ are time-variant parameters for the unwinding roll and decrease with time, (4) can be obtained as follows:

$$
\frac{d}{d t}\left(J_{1}(t) \omega_{1}(t)\right)=\dot{J}_{1}(t) \omega_{1}(t)+J_{1}(t) \dot{\omega}_{1}(t) .
$$

In the actual production process of the gravure printing machine, the thickness of the web is very small compared with the radius of the rollers over which the web is wrapped. Because $R_{1}(t)$ varies gradually over a short period of time, $R_{1}(t)$ and $J_{1}(t)$ vary gradually in comparison with the web dynamics. Hence, the differential of $J_{1}(t)$ can be neglected. As shown in Figure 2, (3) becomes (5) as the following:

$$
\begin{aligned}
J_{1}(t) \dot{\omega}_{1}(t) & =\left(T_{1}(t)-T_{0}\right) R_{1}(t)+C_{1} u_{1}(t)-f \omega_{1}(t), \\
J_{2} \dot{\omega}_{2}(t) & =\left(T_{2}(t)-T_{1}(t)\right) R_{2}+C_{2} u_{2}(t)-f \omega_{2}(t) .
\end{aligned}
$$

As shown in Figure 2, the working process of the dancer roll can cause a change in web length. After analysis, (6) can be obtained as follows:

$$
L_{1}(t)=L_{1}-2 L_{D 2} \theta(t)
$$




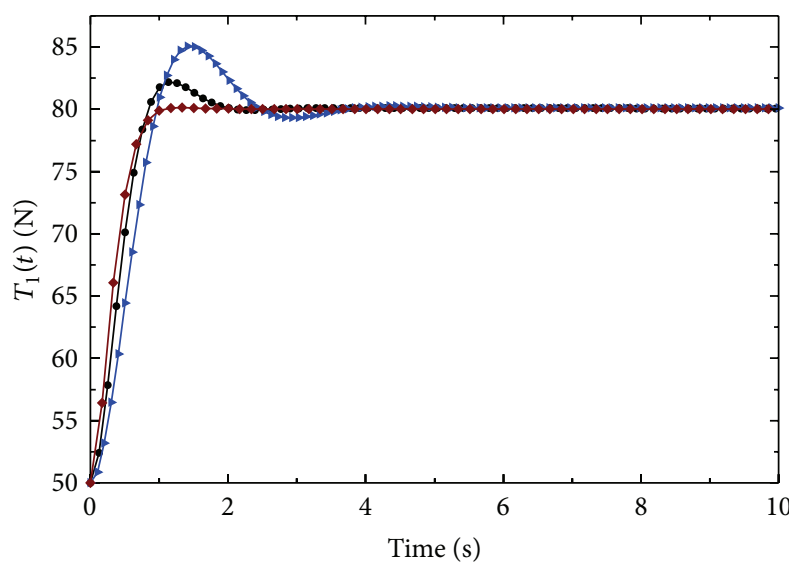

(a) $T_{1}(t)$ with PID controller

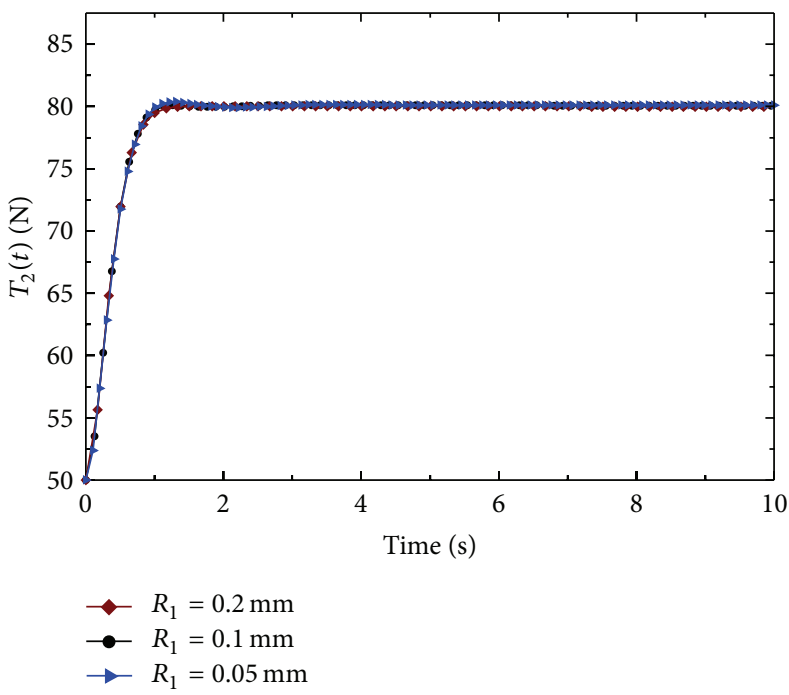

(c) $T_{2}(t)$ with PID controller

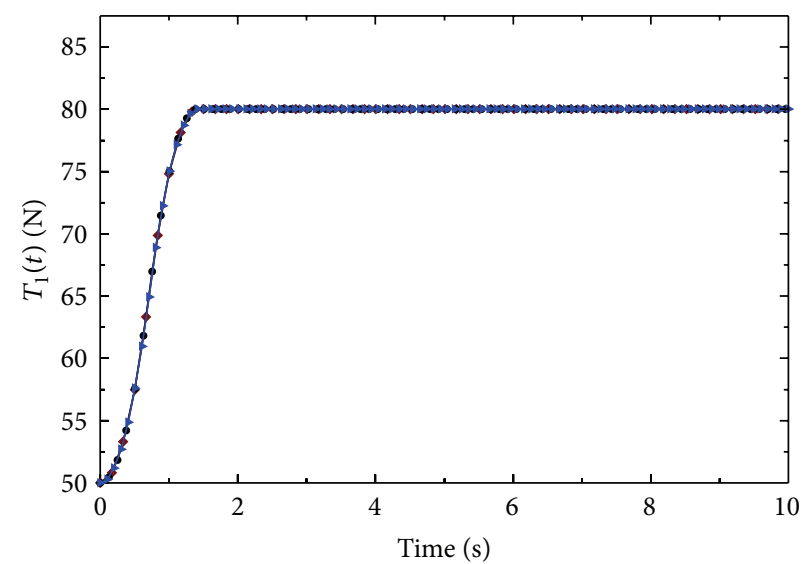

(b) $T_{1}(t)$ with ADRC controller

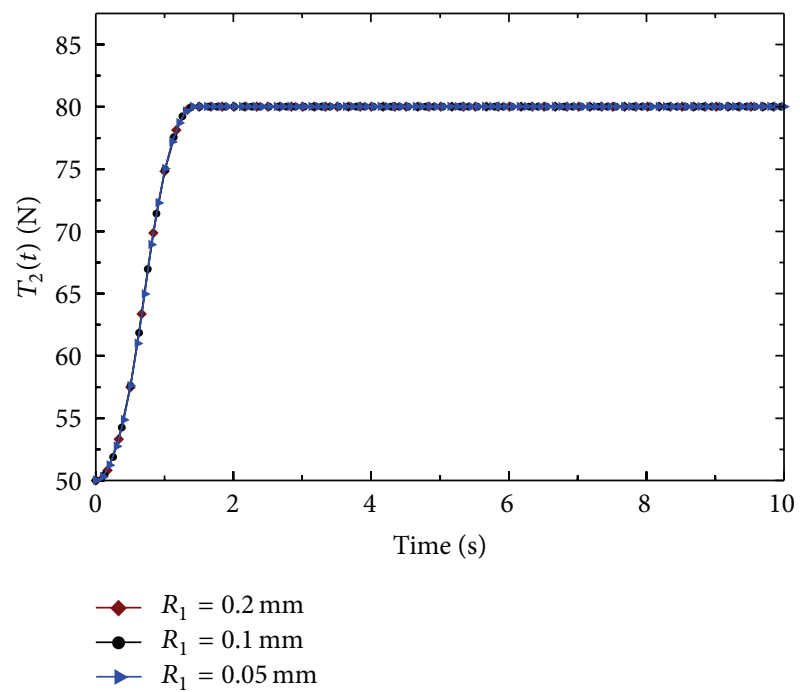

(d) $T_{2}(t)$ with ADRC controller

FIGURE 5: Step response curves for $\omega_{3}=100 \mathrm{r} / \mathrm{min}$.

Combining (6) with (2.2), (2.2) can be rewritten as follows:

$$
\begin{aligned}
\left(L_{1}\right. & \left.-2 L_{D 2} \theta(t)\right) \dot{T}_{1}(t) \\
= & \left(T_{0}-A E\right) R_{1}(t) \omega_{1}(t)+\left(A E-T_{1}(t)\right) R_{2} \omega_{2}(t) \\
& -2 L_{D 2}\left(A E-T_{1}(t)\right) \dot{\theta}(t), \\
L_{2} \dot{T}_{2}(t)= & \left(T_{1}(t)-A E\right) R_{2} \omega_{2}(t)+\left(A E-T_{2}(t)\right) R_{3} \omega_{3} .
\end{aligned}
$$

According to Newton's laws of motion and eliminating the influence of the weight of the dancer roll, the dynamic equation of the dancer roll is expressed as

$$
T_{1}(t)=\frac{1}{2 L_{D 2}}\left(J_{D a} \ddot{\theta}(t)+f_{D} \dot{\theta}(t)+K L_{D 1}^{2} \theta(t)\right) .
$$

Combining (5), (2.2), and (8), the nonlinear mathematical model for the unwinding system is constructed as follows:

$$
\begin{gathered}
J_{1}(t) \dot{\omega}_{1}(t)=\left(T_{1}(t)-T_{0}\right) R_{1}(t)+C_{1} u_{1}(t)-f \omega_{1}(t), \\
J_{2} \dot{\omega}_{2}(t)=\left(T_{2}(t)-T_{1}(t)\right) R_{2}+C_{2} u_{2}(t)-f \omega_{2}(t), \\
2 L_{D 2} T_{1}(t)=J_{D a} \ddot{\theta}(t)+f_{D} \dot{\theta}(t)+K L_{D 1}^{2} \theta(t), \\
\left(L_{1}-2 L_{D 2} \theta(t)\right) \dot{T}_{1}(t) \\
=\left(T_{0}-A E\right) R_{1}(t) \omega_{1}(t)+\left(A E-T_{1}(t)\right) R_{2} \omega_{2}(t) \\
\quad-2 L_{D 2}\left(A E-T_{1}(t)\right) \dot{\theta}(t), \\
L_{2} \dot{T}_{2}(t)=\left(T_{1}(t)-A E\right) R_{2} \omega_{2}(t)+\left(A E-T_{2}(t)\right) R_{3} \omega_{3} .
\end{gathered}
$$

The controlled variables $u_{1}(t)$ and $u_{2}(t)$ of servo motors $M_{1}$ and $M_{2}$, respectively, are the input signals in the unwinding system, and tensions $T_{1}(t)$ and $T_{2}(t)$ are the outputs in the unwinding system. Because both $u_{1}(t)$ and $u_{2}(t)$ have an 


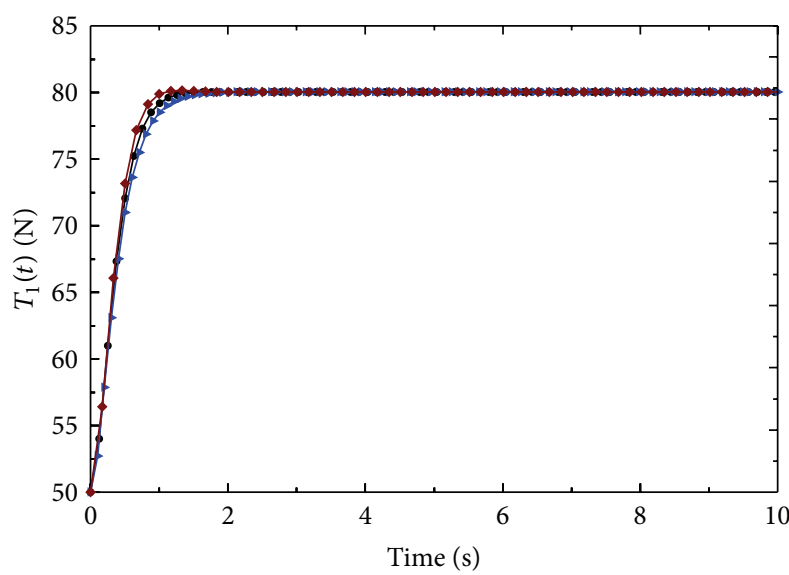

(a) $T_{1}(t)$ with PID controller

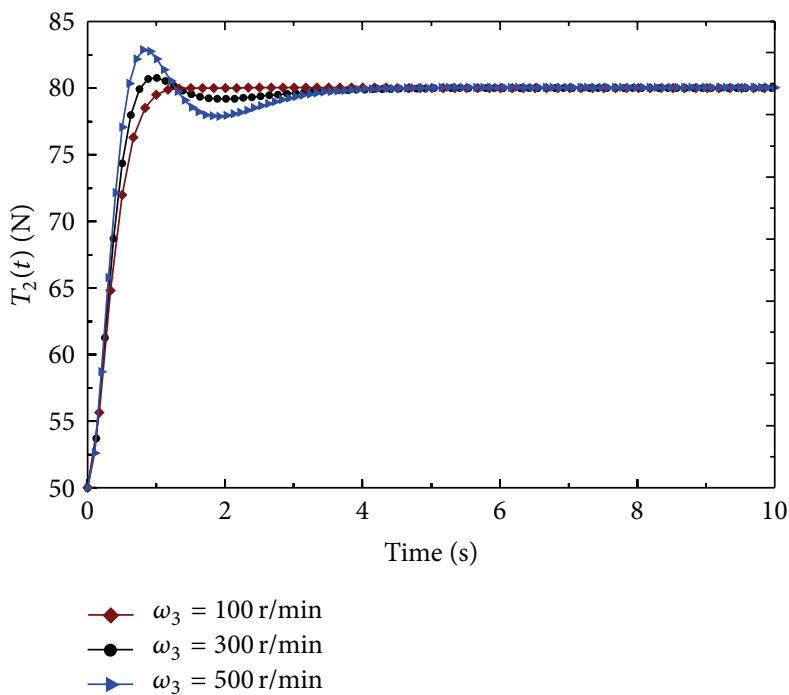

(c) $T_{2}(t)$ with PID controller

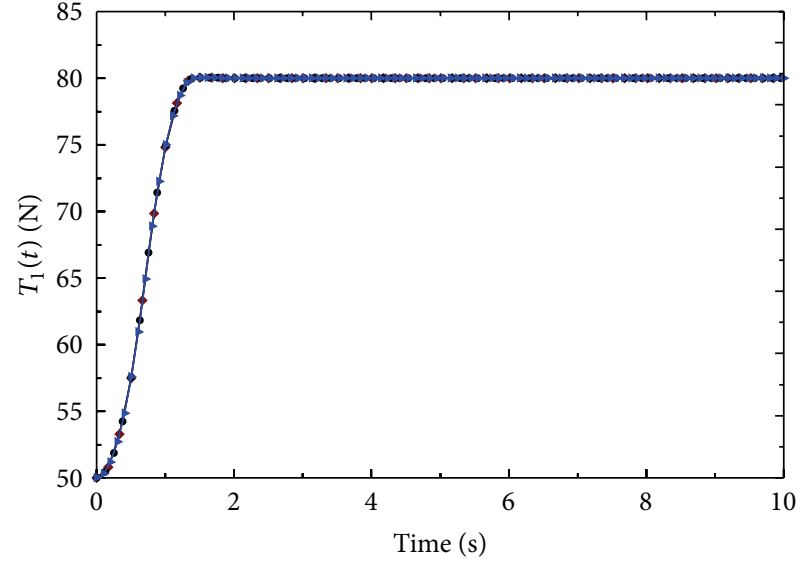

(b) $T_{1}(t)$ with ADRC controller

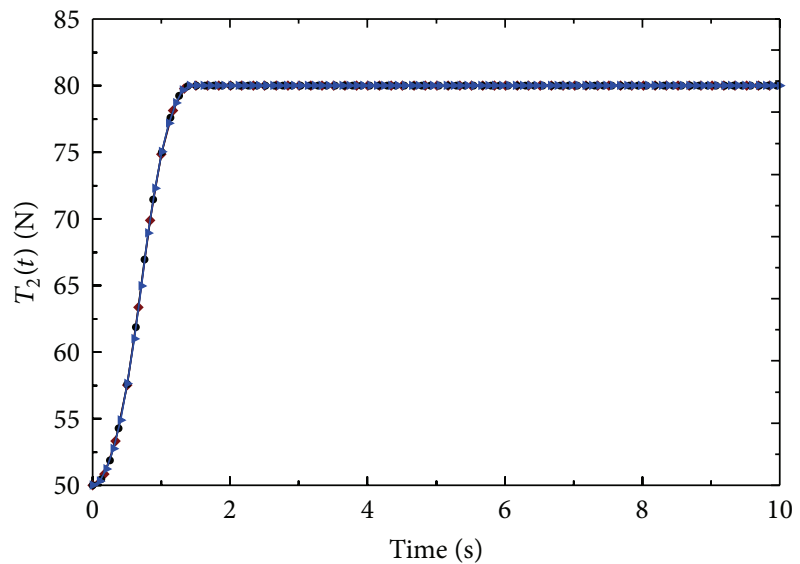

$\multimap \omega_{3}=100 \mathrm{r} / \mathrm{min}$

$\longrightarrow \omega_{3}=300 \mathrm{r} / \mathrm{min}$

$\rightarrow \omega_{3}=500 \mathrm{r} / \mathrm{min}$

(d) $T_{2}(t)$ with ADRC controller

FIgURE 6: Step response curves for $R_{1}=0.2 \mathrm{~m}$.

impact on $T_{1}(t)$ and $T_{2}(t)$, the unwinding system can be characterised as nonlinear, time-varying, multi-input multioutput (MIMO), and coupling.

\section{Proposed ADRC Decoupling Controller}

3.1. Decoupling Model. According to (2.2) and after calculating the second derivative of $T_{1}(t)$ and $T_{2}(t)$, the relationship between the inputs and outputs of the nonlinear model can be represented as follows:

$$
\begin{aligned}
\ddot{T}_{1}(t) & \left(2 L_{D 2}\left[\left(T_{1}(t)-A E\right) \ddot{\theta}(t)+2 \dot{T}_{1}(t) \dot{\theta}(t)\right]\right. \\
& \left.-R_{2} \omega_{2}(t) \dot{T}_{1}(t)+\left(T_{0}-A E\right) \omega_{1}(t) \dot{R}_{1}(t)\right) \\
& \times\left(L_{1}-2 L_{D 2} \theta(t)\right)^{-1} \\
& +\frac{R_{1}(t)\left(T_{0}-A E\right)\left[R_{1}(t)\left(T_{1}(t)-T_{0}\right)-f \omega_{1}(t)\right]}{J_{1}(t)\left(L_{1}-2 L_{D 2} \theta(t)\right)}
\end{aligned}
$$

$+\frac{C_{1} R_{1}(t)\left(T_{0}-A E\right)}{J_{1}(t)\left(L_{1}-2 L_{D 2} \theta(t)\right)} u_{1}(t)$

$+\frac{R_{2}\left(A E-T_{1}(t)\right)\left[R_{2}\left(T_{2}(t)-T_{1}(t)\right)-f \omega_{2}(t)\right]}{J_{2}\left(L_{1}-2 L_{D 2} \theta(t)\right)}$

$+\frac{C_{2} R_{2}\left(A E-T_{1}(t)\right)}{J_{2}\left(L_{1}-2 L_{D 2} \theta(t)\right)} u_{2}(t)$,

$\ddot{T}_{2}(t)$

$$
\begin{aligned}
= & \frac{R_{2} \omega_{2}(t) \dot{T}_{1}(t)-R_{3} \omega_{3} \dot{T}_{2}(t)}{L_{2}} \\
& +\frac{R_{2}\left(T_{1}(t)-A E\right)\left[R_{2}\left(T_{2}(t)-T_{1}(t)\right)-f \omega_{2}(t)\right]}{J_{2} L_{2}} \\
& +\frac{C_{2} R_{2}\left(T_{1}(t)-A E\right)}{J_{2} L_{2}} u_{2}(t) .
\end{aligned}
$$




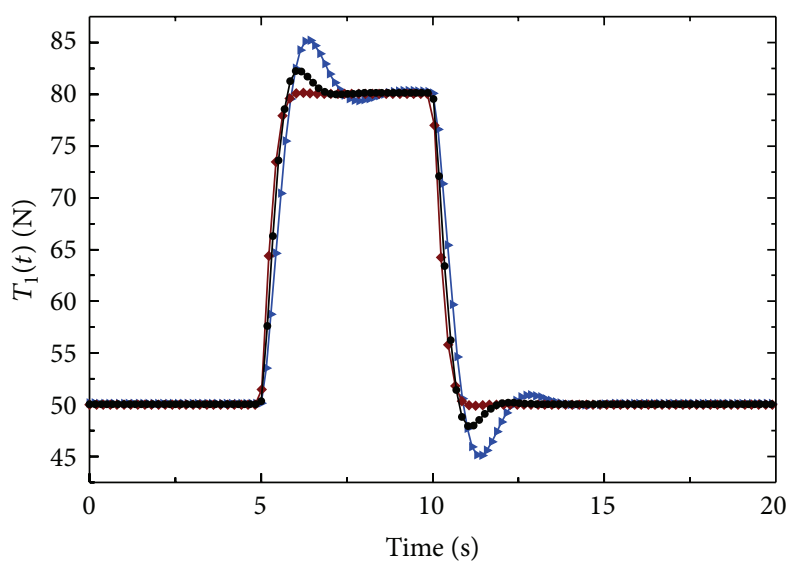

(a) $T_{1}(t)$ with PID controller

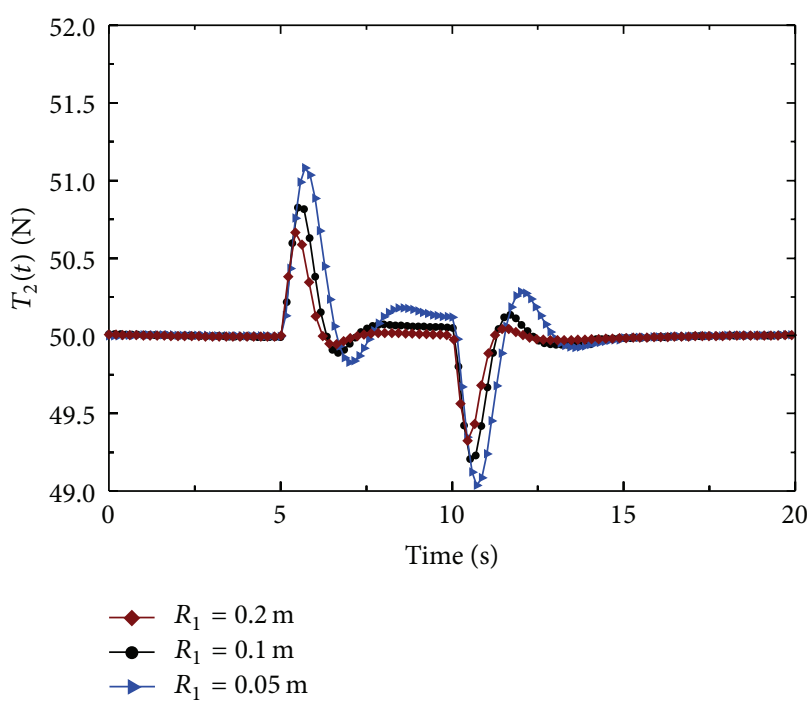

(c) $T_{2}(t)$ with PID controller

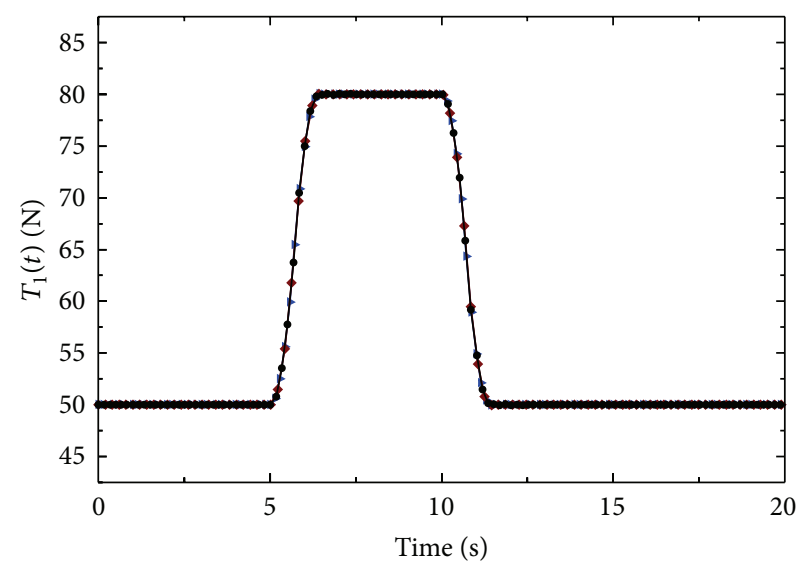

(b) $T_{1}(t)$ with ADRC controller

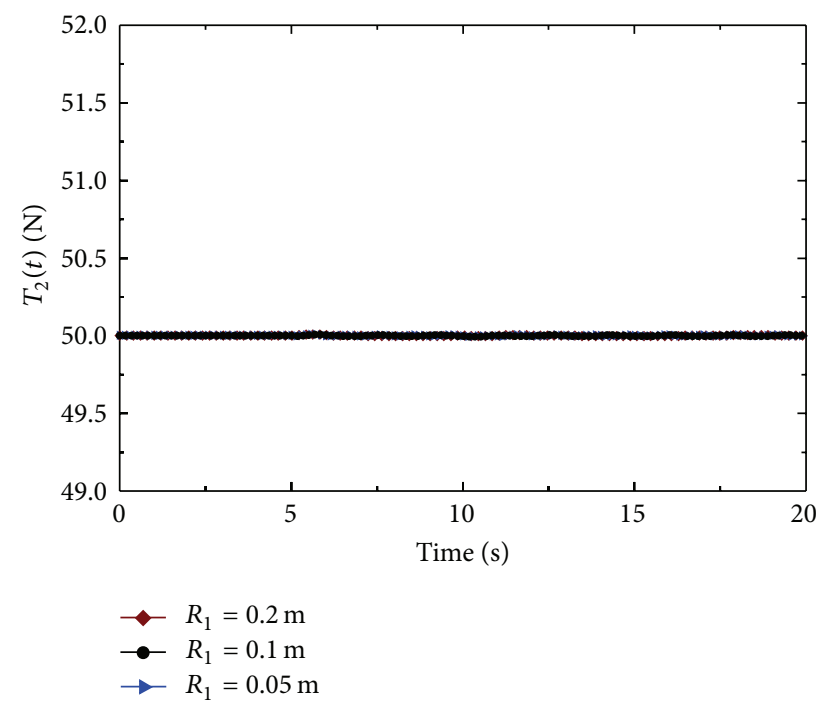

(d) $T_{2}(t)$ with ADRC controller

FIGURE 7: Decoupling response curves for $\omega_{3}=100 \mathrm{r} / \mathrm{min}$.

We define the dynamic coupling vector $\mathbf{f}(t)$ and input matrix $\mathbf{B}(t)$ as follows:

$$
\mathbf{f}(t)=\left[\begin{array}{l}
f_{1}(t) \\
f_{2}(t)
\end{array}\right]
$$

$$
\begin{aligned}
& f_{1}(t) \\
& =\left(2 L_{D 2}\left[\left(T_{1}(t)-A E\right) \ddot{\theta}(t)+2 \dot{T}_{1}(t) \dot{\theta}(t)\right]\right. \\
& \left.\quad-R_{2} \omega_{2}(t) \dot{T}_{1}(t)+\left(T_{0}-A E\right) \omega_{1}(t) \dot{R}_{1}(t)\right) \\
& \quad \times\left(L_{1}-2 L_{D 2} \theta(t)\right)^{-1} \\
& +\frac{R_{1}(t)\left(T_{0}-A E\right)\left[R_{1}(t)\left(T_{1}(t)-T_{0}\right)-f \omega_{1}(t)\right]}{J_{1}(t)\left(L_{1}-2 L_{D 2} \theta(t)\right)} \\
& +\frac{R_{2}\left(A E-T_{1}(t)\right)\left[R_{2}\left(T_{2}(t)-T_{1}(t)\right)-f \omega_{2}(t)\right]}{J_{2}\left(L_{1}-2 L_{D 2} \theta(t)\right)},
\end{aligned}
$$

$$
\begin{aligned}
f_{2}(t)= & \frac{R_{2} \omega_{2}(t) \dot{T}_{1}(t)-R_{3} \omega_{3} \dot{T}_{2}(t)}{L_{2}} \\
& +\frac{R_{2}\left(T_{1}(t)-A E\right)\left[R_{2}\left(T_{2}(t)-T_{1}(t)\right)-f \omega_{2}(t)\right]}{J_{2} L_{2}},
\end{aligned}
$$$$
\mathbf{B}(t)=\left[\begin{array}{cc}
\frac{C_{1} R_{1}(t)\left(T_{0}-A E\right)}{J_{1}(t)\left(L_{1}-2 L_{D 2} \theta(t)\right)} & \frac{C_{2} R_{2}\left(A E-T_{1}(t)\right)}{J_{2}\left(L_{1}-2 L_{D 2} \theta(t)\right)} \\
& \frac{C_{2} R_{2}\left(T_{1}(t)-A E\right)}{J_{2} L_{2}}
\end{array}\right] .
$$

Substituting (11) into (10), (10) can be rewritten as follows:

$$
\left[\begin{array}{l}
\ddot{T}_{1}(t) \\
\ddot{T}_{2}(t)
\end{array}\right]=\mathbf{f}(t)+\mathbf{B}(t)\left[\begin{array}{l}
u_{1}(t) \\
u_{2}(t)
\end{array}\right] .
$$




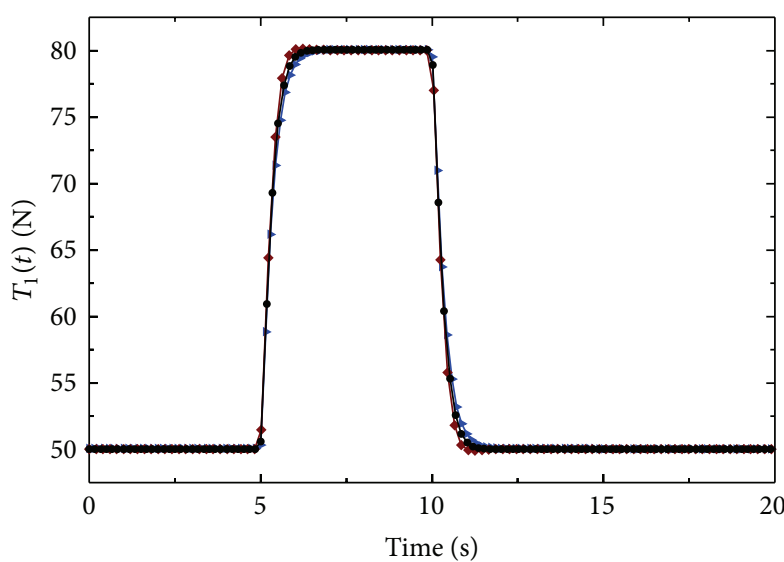

(a) $T_{1}(t)$ with PID controller

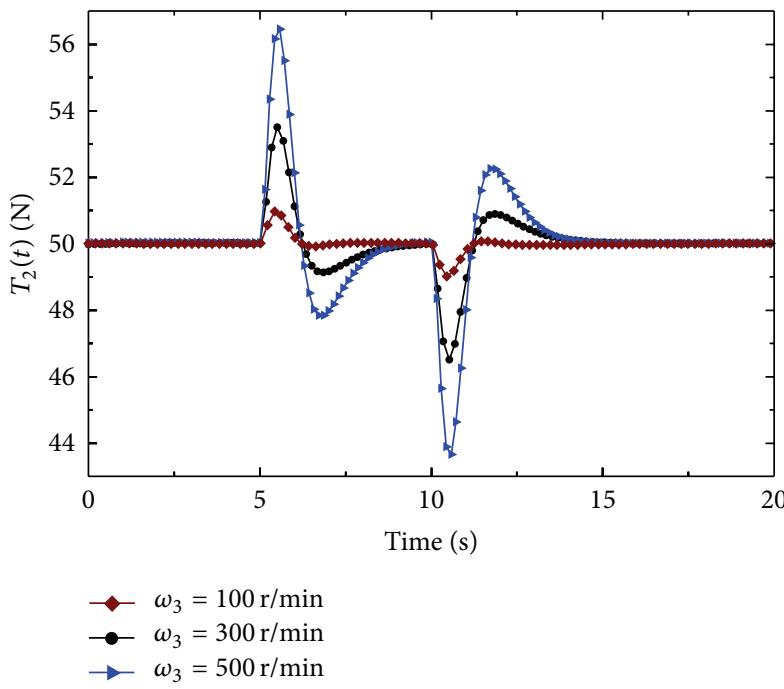

(c) $T_{2}(t)$ with PID controller

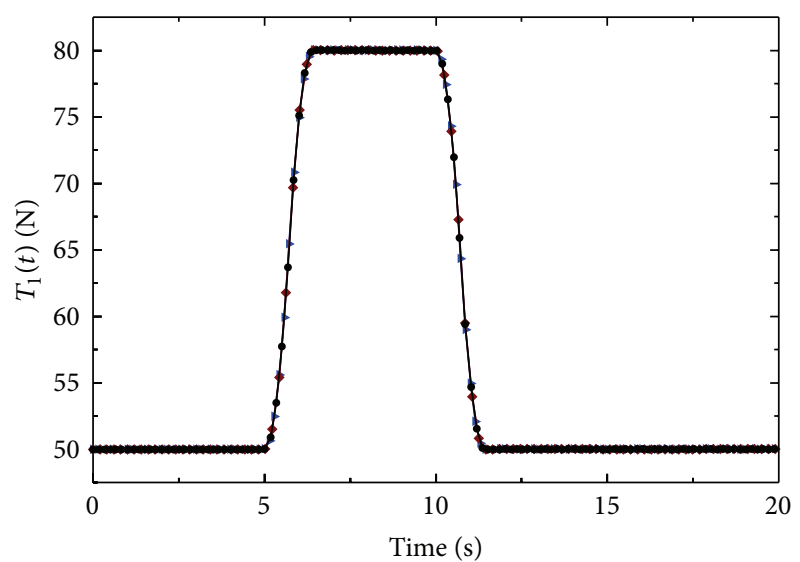

(b) $T_{1}(t)$ with ADRC controller

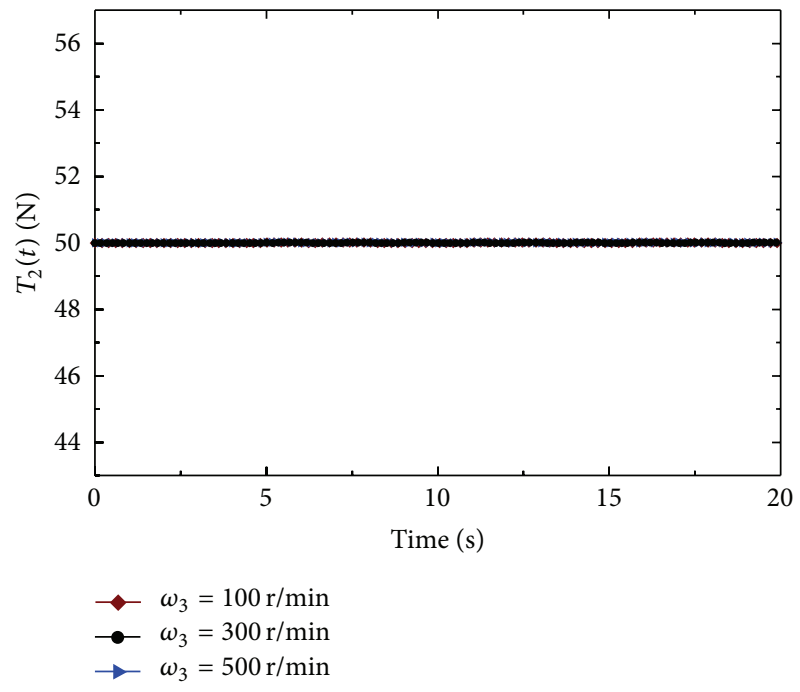

(d) $T_{2}(t)$ with ADRC controller

Figure 8: Decoupling response curves for $R_{1}=0.2 \mathrm{~m}$.

Equation (12) illustrates that the unwinding system of the gravure printing machines is a second-order coupling system with two inputs and two outputs. In this study, we define the virtual control quantities $\tau_{1}(t)$ and $\tau_{2}(t)$ as follows:

$$
\left[\begin{array}{l}
\tau_{1}(t) \\
\tau_{2}(t)
\end{array}\right]=\mathbf{B}(t)\left[\begin{array}{l}
u_{1}(t) \\
u_{2}(t)
\end{array}\right] .
$$

Combining (12) and (13), the nonlinear mathematical model for the unwinding system can also be rewritten as follows:

$$
\left[\begin{array}{l}
\ddot{T}_{1}(t) \\
\ddot{T}_{2}(t)
\end{array}\right]=\mathbf{f}(t)+\left[\begin{array}{l}
\tau_{1}(t) \\
\tau_{2}(t)
\end{array}\right] .
$$

Because the dynamic coupling vector $\mathbf{f}(t)$ in the ADRC framework can be actively estimated and compensated in real time, the relationships between the virtual control quantities $\tau_{1}(t)$ and $\tau_{2}(t)$ and the controlled output variables $T_{1}(t)$ and $T_{2}(t)$ are single-input, single-output, and also decoupled, as shown in (14).
In this work, because $T_{0} \ll A E, T_{1}(t) \ll A E$, and $2 L_{D 2} \theta(t) \ll L_{1}$, so (15) can be got as follows:

$$
|\mathbf{B}(t)|=\frac{C_{1} C_{2} R_{2} R_{1}(t)\left(T_{0}-A E\right)\left(T_{1}(t)-A E\right)}{J_{2} L_{2} J_{1}(t)\left(L_{1}-2 L_{D 2} \theta(t)\right)} \neq 0 .
$$

So $\mathbf{B}(t)$ is an invertible matrix.

Therefore, the relationships between the virtual control quantities $\tau_{1}(t)$ and $\tau_{2}(t)$ and the actual control variables $u_{1}(t)$ and $u_{2}(t)$ can be expressed as

$$
\left[\begin{array}{l}
u_{1}(t) \\
u_{2}(t)
\end{array}\right]=\mathbf{B}^{-1}(t)\left[\begin{array}{l}
\tau_{1}(t) \\
\tau_{2}(t)
\end{array}\right],
$$

where matrix $\mathbf{B}^{-\mathbf{1}}(t)$ is the decoupling plant of the unwinding system as follows:

$$
\mathbf{B}^{-1}(t)=\left[\begin{array}{cc}
\frac{J_{1}(t)\left(L_{1}-2 L_{D 2} \theta(t)\right)}{C_{1} R_{1}(t)\left(T_{0}-A E\right)} & \frac{L_{2} J_{1}(t)}{C_{1} R_{1}(t)\left(T_{0}-A E\right)} \\
& \frac{J_{2} L_{2}}{C_{2} R_{2}\left(T_{1}(t)-A E\right)}
\end{array}\right] .
$$




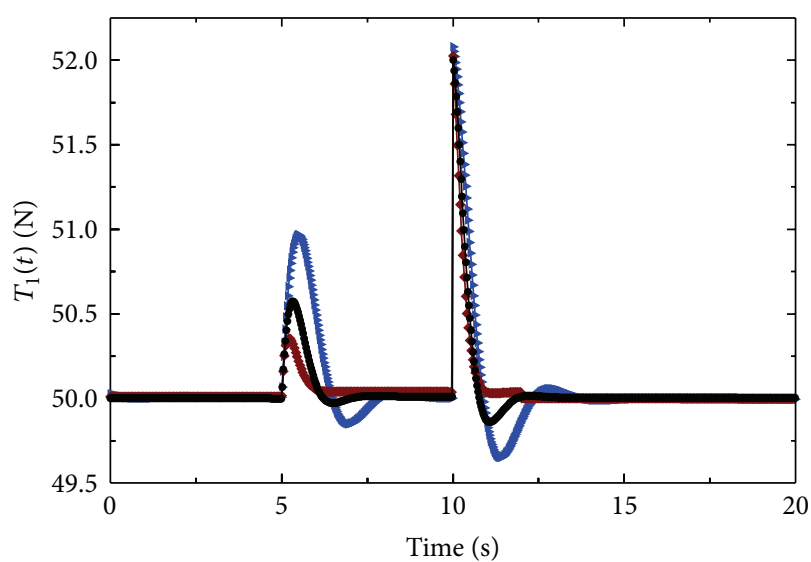

(a) $T_{1}(t)$ with PID controller

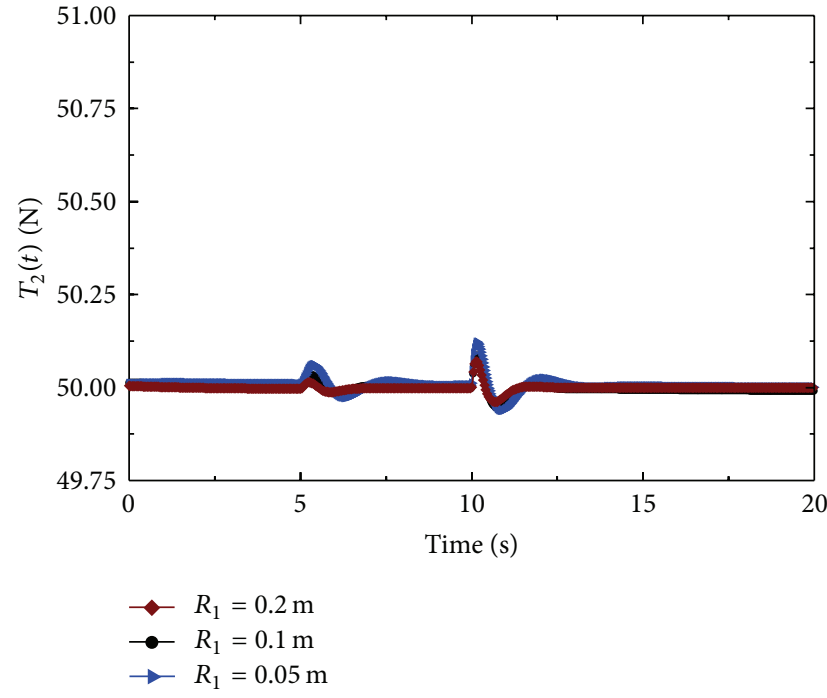

(c) $T_{2}(t)$ with PID controller

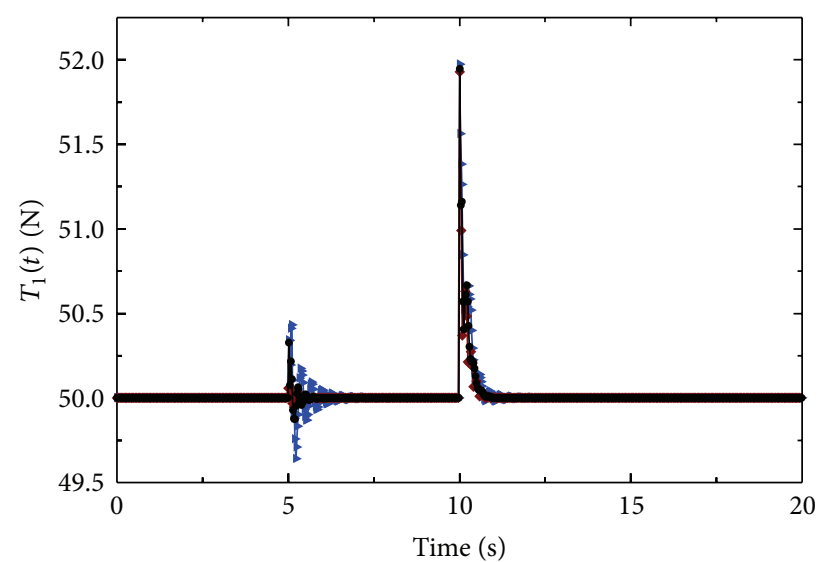

(b) $T_{1}(t)$ with ADRC controller

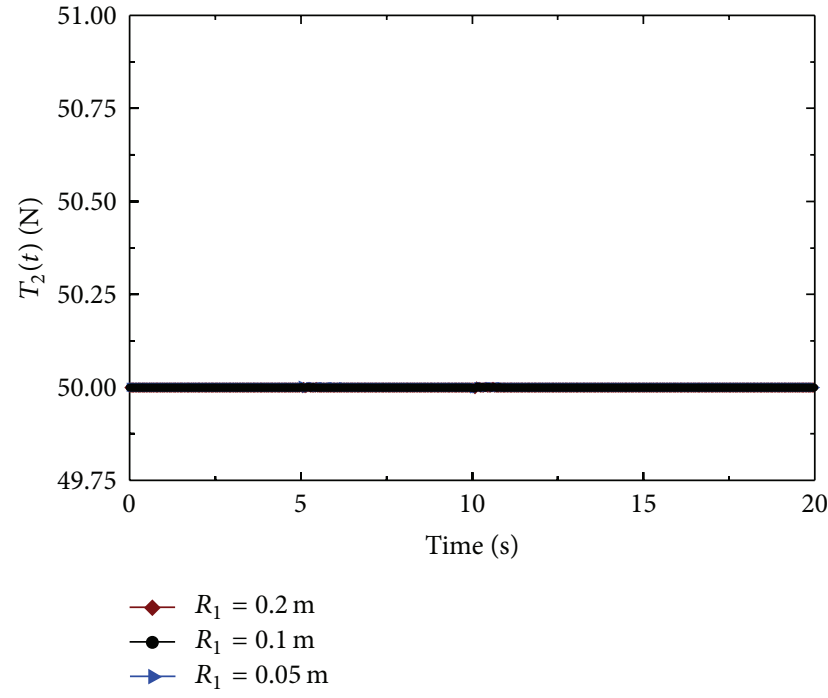

(d) $T_{2}(t)$ with ADRC controller

FIgURE 9: Antidisturbance curves for $\omega_{3}=100 \mathrm{r} / \mathrm{min}$.

3.2. ADRC Decoupling Control Methodology. Based on the order and decoupling plant of the unwinding system, an ADRC decoupling control methodology is designed to enhance tension stability, as shown in Figure 3. ADRC1 and ADRC2 are relevant to $T_{1}(t)$ and $T_{2}(t)$, respectively, for constant tension control. Because the unwinding system is a second-order system, two second-order ADRC controllers are needed. Each ADRC controller consists of a second-order tracking differentiator (TD), a third-order extended state observer (ESO), and a nonlinear state error feedback (NLSEF).

The second-order TD is a nonlinear component; given an input signal, we can acquire a corresponding tracking input signal and an approximately differentiated input signal, even for a nondifferentiable or noncontinuous input signal. As shown in Figure $3, v_{11}$ and $v_{21}$ are tracking signals of $T_{1 \text { ref }}$ and $T_{2 \text { ref }}$, respectively, and $v_{12}$ and $v_{22}$ are approximately differentiated signals of $T_{1 \text { ref }}$ and $T_{2 \text { ref }}$, respectively. According to [22], the discrete forms of second-order $\operatorname{TD} i(i=1,2)$ are expressed as

$$
\begin{gathered}
f h_{i}=\text { fhan }\left(v_{i 1}(k)-T_{i \text { ref }}(k), v_{i 2}(k), r_{i}, h\right), \\
v_{i 1}(k+1)=v_{i 1}(k)+h v_{i 2}(k),
\end{gathered}
$$

$$
v_{i 2}(k+1)=v_{i 2}(k)+h f h_{i},
$$

where $r_{i}$ is the velocity factor; $h$ is the sampling step; and fhan $\left(x_{1}, x_{2}, r, h\right)$ is the time-optimal control synthesis function defined as follows:

$$
\begin{gathered}
d=r h ; \quad d_{0}=h d ; \quad y=x_{1}+h x_{2}, \\
a_{0}=\sqrt{d^{2}+8 r|y|}, \\
a= \begin{cases}x_{2}+\frac{a_{0}-d}{y^{2}} \operatorname{sign}(y), & |y|>d_{0}, \\
x_{2}+\frac{y}{h}, & |y| \leq d_{0},\end{cases} \\
\text { fhan }\left(x_{1}, x_{2}, r, h\right)=- \begin{cases}r \operatorname{sign}(a), & |a|>d, \\
r \frac{a}{d}, & |a| \leq d .\end{cases}
\end{gathered}
$$

The third-order ESO is the core of the ADRC, and it not only tracks system output variables and their differentiated signals but also actively estimates dynamic coupling and 


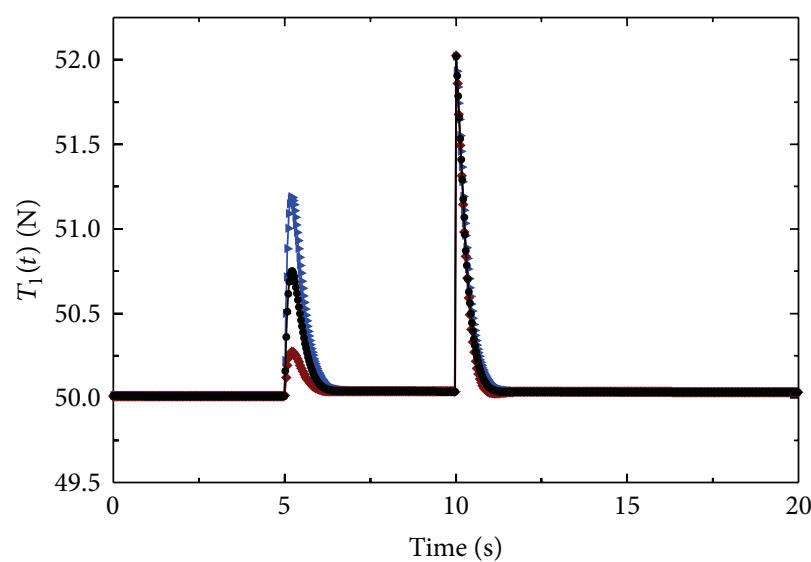

(a) $T_{1}(t)$ with PID controller

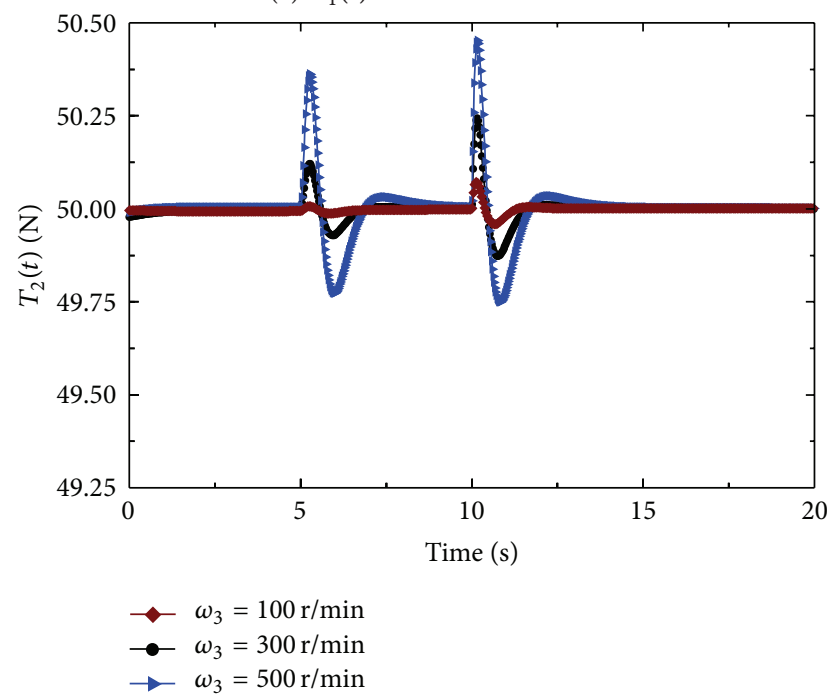

(c) $T_{2}(t)$ with PID controller

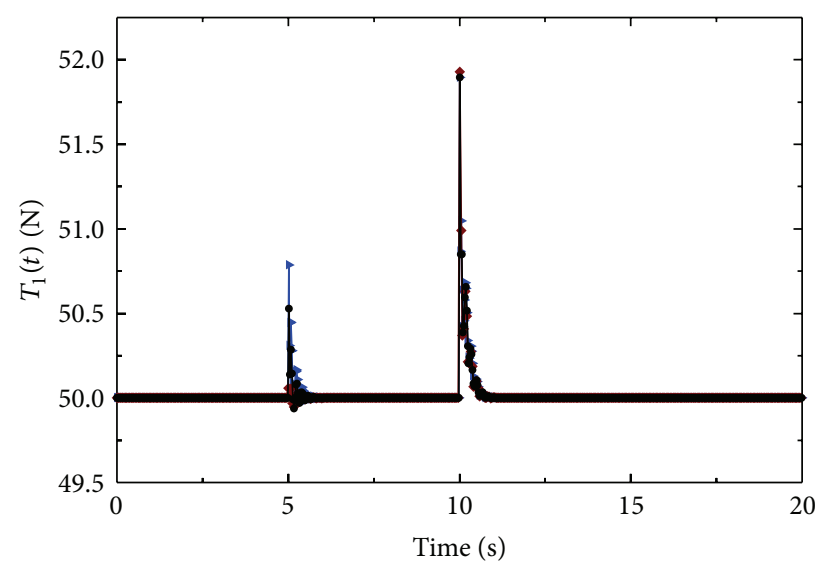

(b) $T_{1}(t)$ with ADRC controller

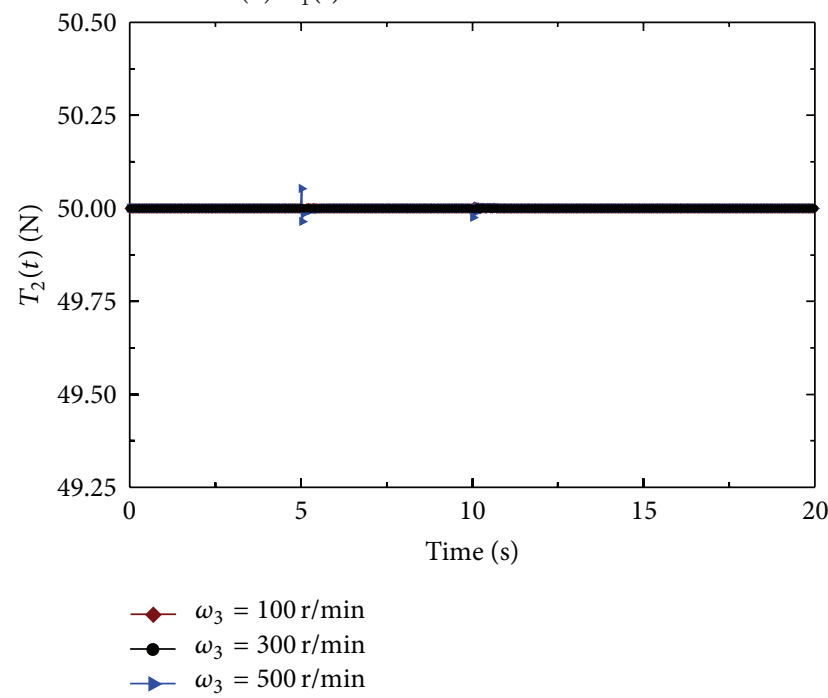

(d) $T_{2}(t)$ with ADRC controller

FIgURE 10: Antidisturbance curves for $R_{1}=0.2 \mathrm{~m}$.

external disturbances in real time. As shown in Figure 3, $z_{11}$ and $z_{21}$ track the output variables $T_{1}(t)$ and $T_{2}(t)$, respectively; $z_{12}$ and $z_{22}$ estimate the differentiated signals of $T_{1}(t)$ and $T_{2}(t)$, respectively; and $z_{13}$ and $z_{23}$ actively estimate $f_{1}(t)$ and $w_{1}(t)$ and $f_{2}(t)$ and $w_{2}(t)$, respectively. The $z_{13}$ and $z_{23}$ variables are considered to be extended states of the system. According to [22], the discrete forms of third-order ESO $i$ ( $i=$ $1,2)$ are expressed as

$$
\begin{gathered}
e_{i}(k)=z_{i 1}(k)-T_{i}(k), \\
z_{i 1}(k+1)=z_{i 1}(k)+h\left(z_{i 2}(k)-\beta_{i 1} e_{i}(k)\right), \\
z_{i 2}(k+1)=z_{i 2}(k) \\
+h\left(z_{i 3}(k)-\beta_{i 2} \operatorname{fal}\left(e_{i}(k), 0.5, \delta\right)+\tau_{i}(k)\right), \\
z_{i 3}(k+1)=z_{i 3}(k)-h \beta_{i 3} \operatorname{fal}\left(e_{i}(k), 0.25, \delta\right),
\end{gathered}
$$

where $\beta_{i 1}, \beta_{i 2}$, and $\beta_{i 3}$ are the ESO gains; $\delta$ is the intervallength of the linear segment; and fal $(e, \alpha, \delta)$ is a nonlinear function defined as follows:

$$
\operatorname{fal}(e, \alpha, \delta)= \begin{cases}\frac{e}{\delta^{1-\alpha}}, & |e| \leq \delta, \\ |e|^{\alpha} \operatorname{sign}(e), & |e|>\delta .\end{cases}
$$

The NLSEF is a nonlinear combination of the resulting differences of the state variables and estimations generated by the TD and ESO, respectively, as shown in Figure 3. The con trol law actively compensates for dynamic coupling and exter nal disturbances that are estimated by the ESO in real time. According to [22], the discrete forms of NLSEFi $(i=1,2)$ are defined as

$$
\begin{gathered}
e_{i 1}(k)=v_{i 1}(k)-z_{i 1}(k), \\
e_{i 2}(k)=v_{i 2}(k)-z_{i 2}(k), \\
\tau_{0 i}(k)=k_{i p} \mathrm{fal}\left(e_{i 1}(k), 0.5, \delta\right)+k_{i d} \mathrm{fal}\left(e_{i 2}(k), 1.5, \delta\right), \\
\tau_{i}(k)=\tau_{0 i}-\frac{z_{i 3}(k)}{b_{0 i}},
\end{gathered}
$$




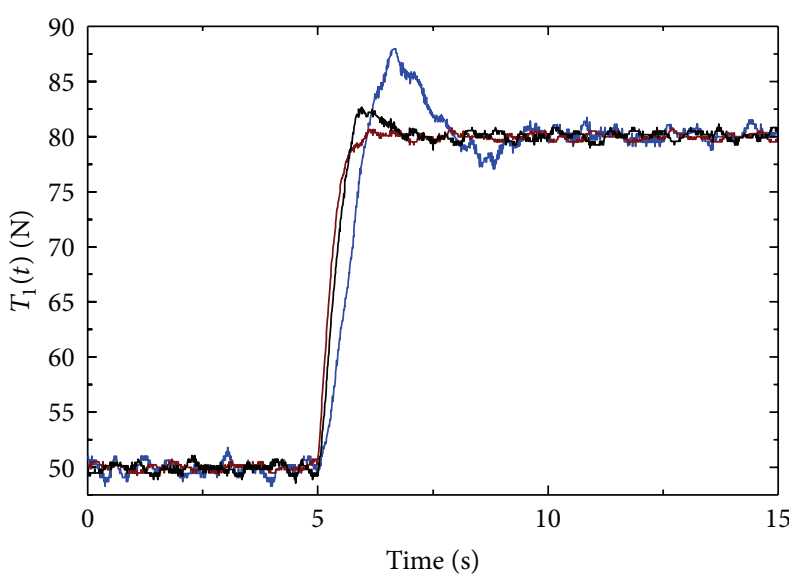

(a) $T_{1}(t)$ with PID controller

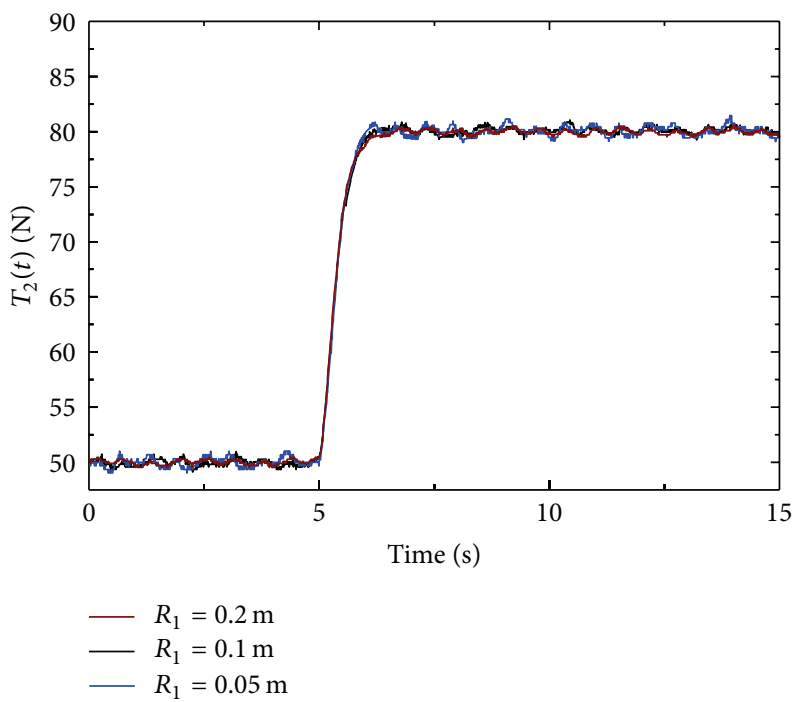

(c) $T_{2}(t)$ with PID controller

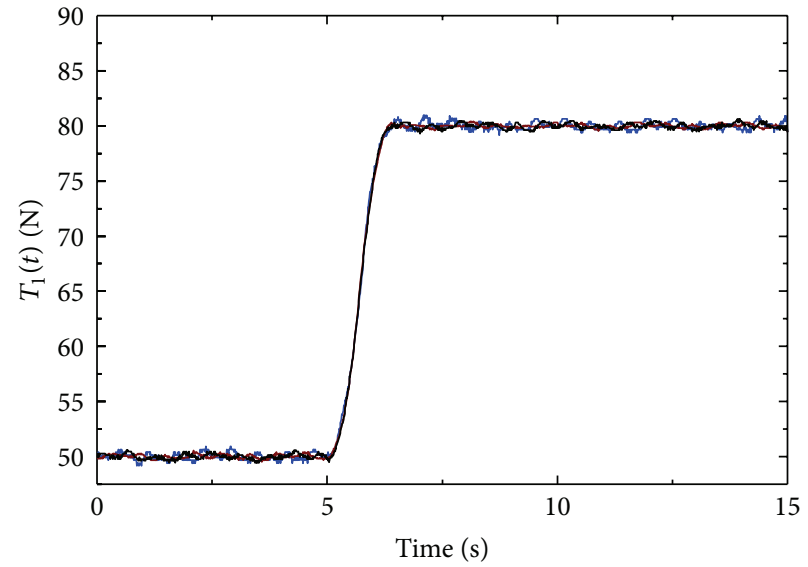

(b) $T_{1}(t)$ with ADRC controller

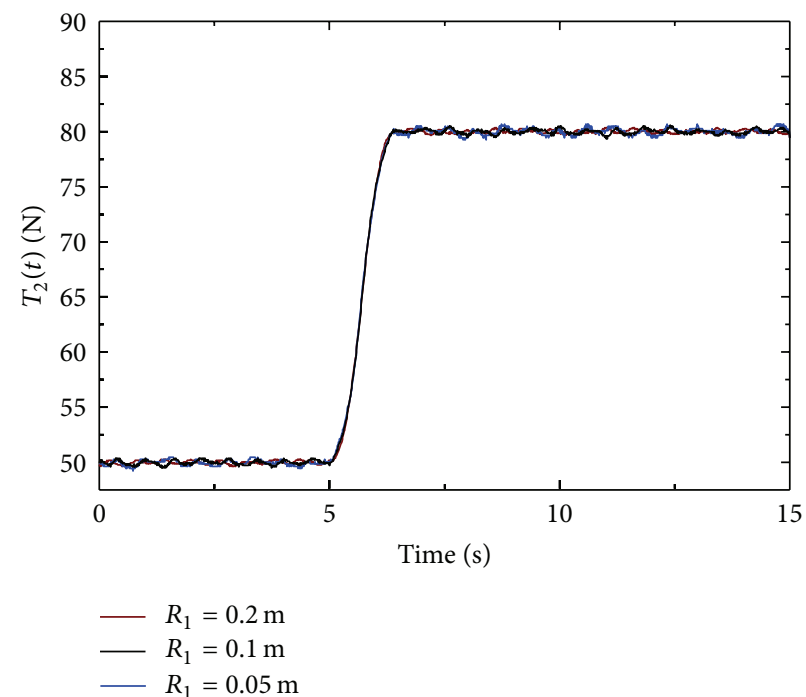

(d) $T_{2}(t)$ with ADRC controller

FIGURE 11: Step response curves for $\omega_{3}=100 \mathrm{r} / \mathrm{min}$.

where $k_{i p}$ is the proportionality coefficient; $k_{i d}$ is the differential coefficient; and $b_{0 i}$ is the compensating factor.

Combining (3.2), (20), and (22), the discrete algorithm of the ADRC $i(i=1,2)$ is shown in

$$
\begin{gathered}
f h_{i}(k)=\text { fhan }\left(v_{i 1}(k)-T_{i \mathrm{ref}}(k), v_{i 2}(k), r_{i}, h\right), \\
v_{i 1}(k+1)=v_{i 1}(k)+h v_{i 2}(k), \\
v_{i 2}(k+1)=v_{i 2}(k)+h f h_{i}(k), \\
e_{i}(k)=z_{i 1}(k)-T_{i}(k), \\
z_{i 1}(k+1)=z_{i 1}(k)+h\left(z_{i 2}(k)-\beta_{i 1} e_{i}(k)\right), \\
z_{i 2}(k+1)=z_{i 2}(k) \\
+h\left(z_{i 3}(k)-\beta_{i 2} \mathrm{fal}\left(e_{i}(k), 0.5, h\right)+\tau_{i}(k)\right), \\
z_{i 3}(k+1)=z_{i 3}(k)-h \beta_{i 3} \mathrm{fal}\left(e_{i}(k), 0.25, h\right), \\
e_{i 1}(k+1)=v_{i 1}(k+1)-z_{i 1}(k+1),
\end{gathered}
$$

$$
\begin{gathered}
e_{i 2}(k+1)=v_{i 2}(k+1)-z_{i 2}(k+1), \\
\tau_{i}(k+1)=k_{i p} \mathrm{fal}\left(e_{i 1}(k+1), 0.5, \delta\right) \\
+k_{\mathrm{id}} \mathrm{fal}\left(e_{i 2}(k+1), 1.5, \delta\right)-\frac{z_{i 3}(k+1)}{b_{0 i}} .
\end{gathered}
$$

After calculating the virtual control variables $\tau_{1}(t)$ and $\tau_{2}(t)$ with the ADRC controller, the actual control variables $u_{1}(t)$ and $u_{2}(t)$ can be obtained by (16).

Two diagrams are provided in Figures 3 and 4 that show the differences between PID and ADRC control synthesis methodology for tension decoupling control of the unwinding system. First, the total disturbance in the ADRC methodology, which includes the external disturbances $\left(w_{1}(t)\right.$ and $\left.w_{2}(t)\right)$, dynamic coupling components of the system $(\mathbf{f}(t))$, and unknown internal dynamics, is defined as an extended state $\left(z_{i 3}\right)$ of the system. The total disturbance can be actively estimated by ESO in real time and compensated in the 


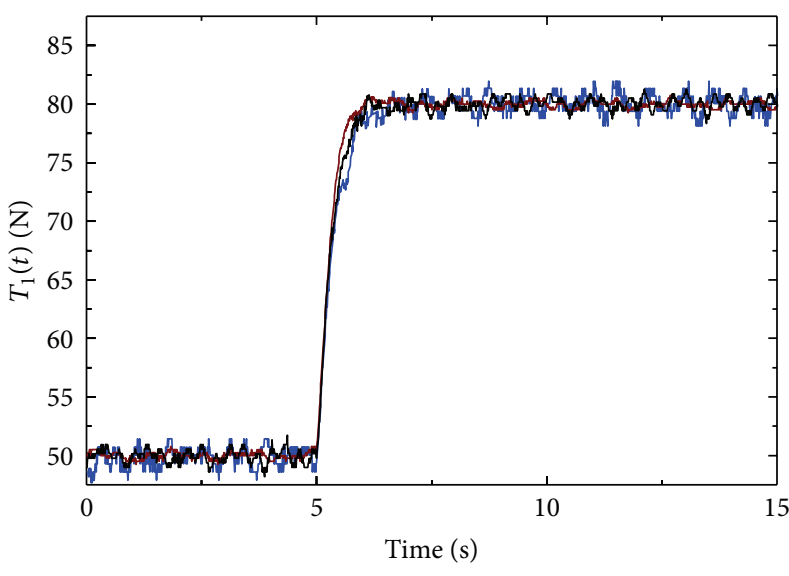

(a) $T_{1}(t)$ with PID controller

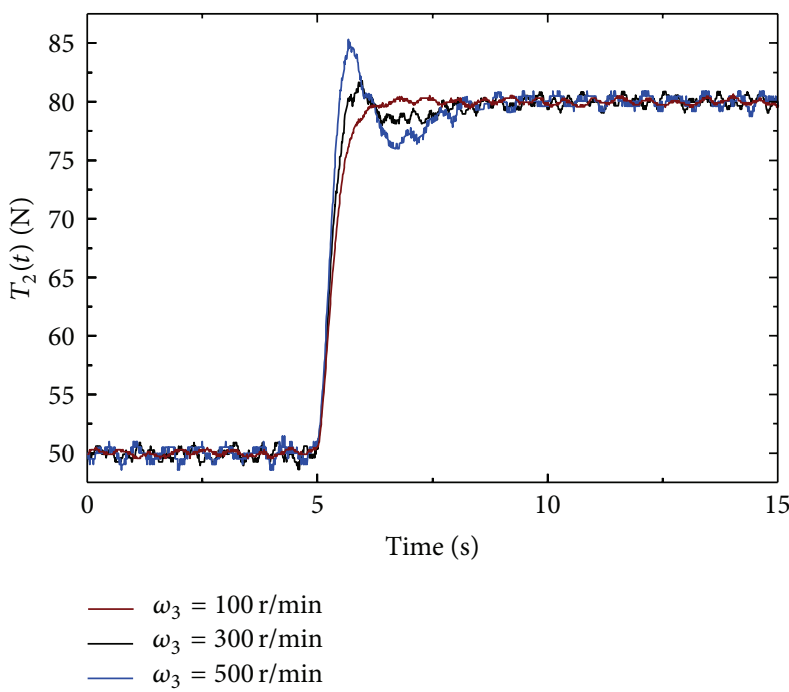

(c) $T_{2}(t)$ with PID controller

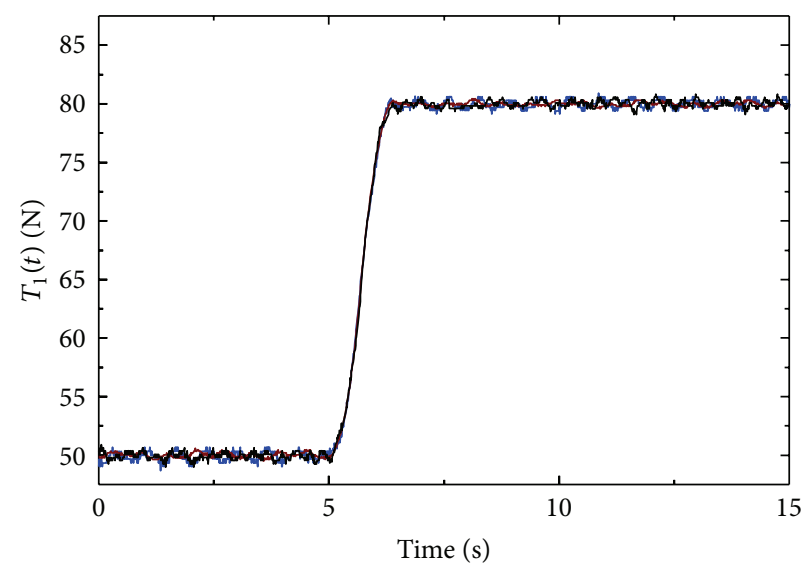

(b) $T_{1}(t)$ with ADRC controller

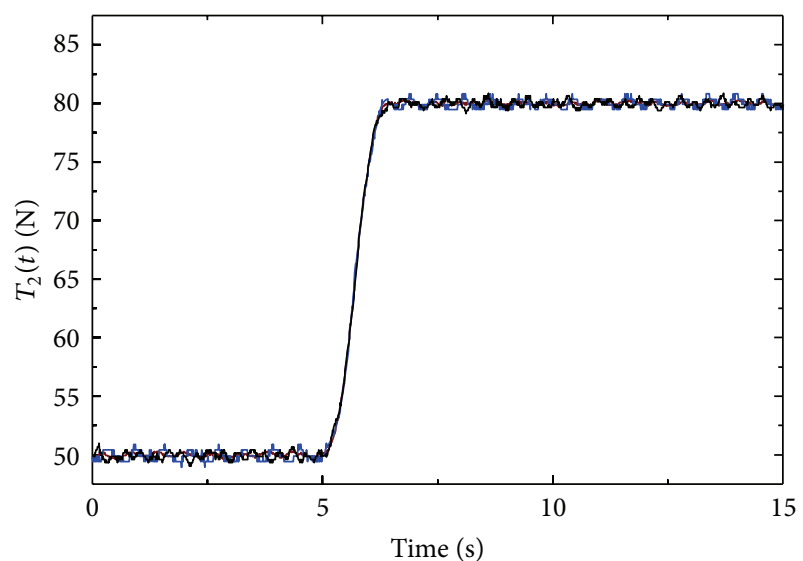

$\begin{aligned}-\omega_{3} & =100 \mathrm{r} / \mathrm{min} \\ -\omega_{3} & =300 \mathrm{r} / \mathrm{min} \\ -\omega_{3} & =500 \mathrm{r} / \mathrm{min}\end{aligned}$

(d) $T_{2}(t)$ with ADRC controller

FIGURE 12: Step response curves for $R_{1}=0.2 \mathrm{~m}$.

corresponding control signal in each sampling period. However, in PID methodology, the total disturbance is managed passively by parameter tuning. Second, because the differentiated signals $v_{i 2}$ and $z_{i 2}$ are obtained by the TD and ESO, respectively, in ADRC methodology, the errors of the differentiation are not produced by direct differentiation of the inputs and the outputs. This attribute makes the ADRC algorithm less sensitive to discontinuities in the inputs and noise in the outputs. However, due to noise sensitivity, PID methodology is often implemented without the derivative component.

\section{Simulation and Experiments}

To investigate the performance of the proposed ADRC decoupling control methodology, a comparison of the unwinding systems of PID and ADRC control strategies was performed through simulation and experiments. The parameters of the unwinding system used in the simulation and experiments are summarised in Table 1. All parameters of ADRC and PID were determined at $\omega_{3}=100 \mathrm{r} / \mathrm{min}$ and $R_{1}=0.2 \mathrm{~m}$.
TABLE 1: Mechanical parameters of the unwinding system.

\begin{tabular}{lcc}
\hline Parameters & Value & Units \\
\hline$L_{1}$ & 1 & $\mathrm{~m}$ \\
$L_{2}$ & 0.35 & $\mathrm{~m}$ \\
$A$ & $5 \times 10^{-6}$ & $\mathrm{~m}^{2}$ \\
$L_{D 1}$ & 0.064 & $\mathrm{~m}$ \\
$L_{D 2}$ & 0.128 & $\mathrm{~m}$ \\
$R_{2}$ & 0.03 & $\mathrm{~m}$ \\
$R_{3}$ & 0.03 & $\mathrm{~m}$ \\
$E$ & $1.6 \times 10^{8}$ & $\mathrm{~Pa}$ \\
$K$ & $1 \times 10^{4}$ & $\mathrm{~N} / \mathrm{m}$ \\
\hline
\end{tabular}

Although the tests were conducted under different operating conditions, particularly for different unwinding diameters, the parameters remain constant.

4.1. Simulation Results. MATLAB simulation models were constructed to test the performance of the ADRC and PID 


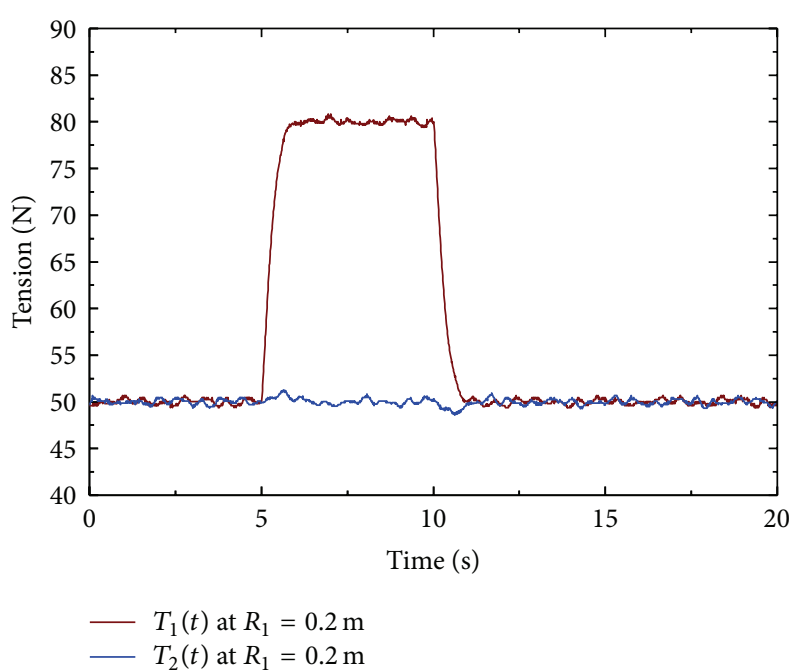

(a) Tension with PID controller

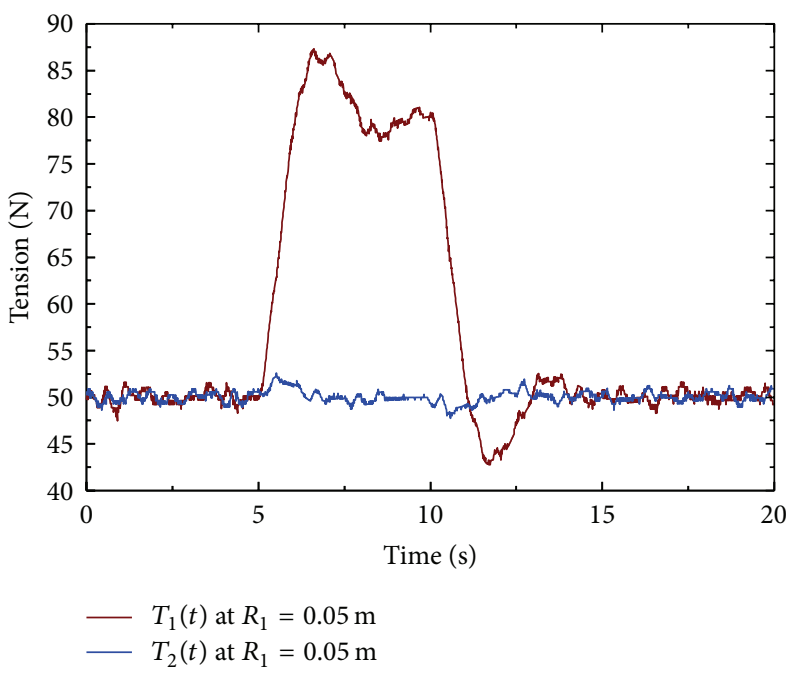

(c) Tension with PID controller

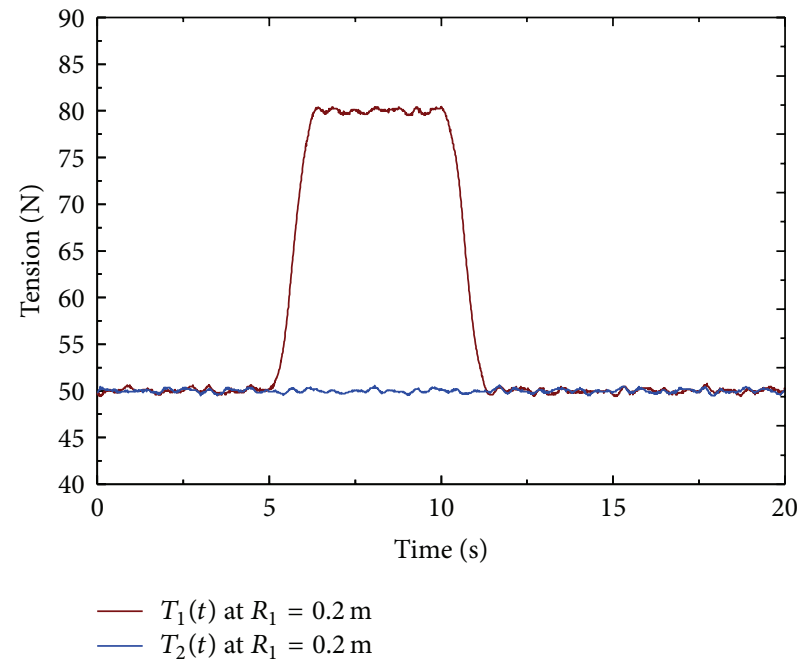

(b) Tension with ADRC controller

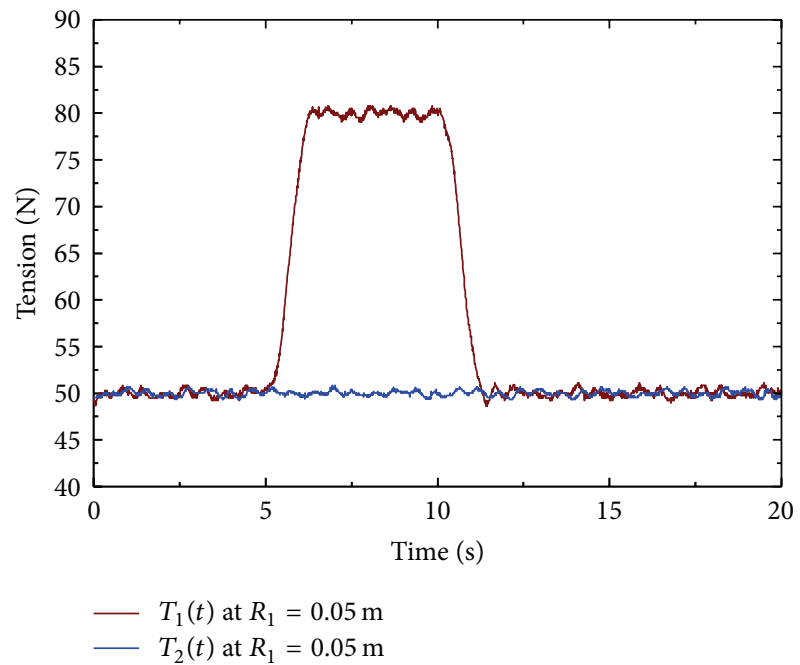

(d) Tension with ADRC controller

FIGURE 13: Decoupling response curves for $\omega_{3}=100 \mathrm{r} / \mathrm{min}$.

TABLE 2: Controller parameters in simulation.

\begin{tabular}{lc}
\hline Controller & Controller parameters \\
\hline ADRC1 & $\beta_{11}=100, \beta_{12}=5560, \beta_{13}=81200$, \\
& $k_{1 p}=920, k_{1 d}=760, r_{1}=60$ \\
ADRC2 & $\beta_{21}=100, \beta_{22}=2870, \beta_{23}=51600$, \\
& $k_{2 p}=3460, k_{2 d}=750, r_{2}=60$ \\
PID1 & $K_{1 p}=30, K_{1 i}=2.5, K_{1 d}=12$ \\
PID2 & $K_{2 p}=65, K_{2 i}=32, K_{2 d}=5$ \\
\hline
\end{tabular}

control strategies. The simulation adopted a fixed-step size mode; the fixed-step size is $10 \mathrm{~ms}$. According to [22, 30, 32], the adjusted parameters of the ADRC are listed in Table 2. The adjusted parameters of the PID are also listed in Table 2.

4.1.1. Case A: Robustness against Dynamic Changes. To verify the robustness against dynamic changes of the developed
ADRC control methodology, the $T_{1}(t)$ and $T_{2}(t)$ step change is from $50 \mathrm{~N}$ to $80 \mathrm{~N}$ when $\omega_{3}$ is equal to $100 \mathrm{r} / \mathrm{min}$ and $R_{1}$ is equal to $0.2 \mathrm{~m}$. The simulation behaviours of the PID and ADRC controllers are shown in Figures 5 and 6.

As shown in Figure 5, when $R_{1}$ is equal to $0.2 \mathrm{~m}, 0.1 \mathrm{~m}$, or $0.05 \mathrm{~m}$, both $T_{1}(t)$ and $T_{2}(t)$ quickly reach $80 \mathrm{~N}$ without overshoot or oscillation in the ADRC controller. However, in the PID controller, a decrease in $R_{1}$ leads to deterioration in the control abilities of $T_{1}(t)$ and $T_{2}(t)$. For example, when $R_{1}$ is equal to $0.05 \mathrm{~m}, T_{1}(t)$ demonstrates an overshoot of approximately $6.38 \%$ and arrives at $80 \mathrm{~N}$ after $4 \mathrm{~s}$. Figure 6 illustrates that when $\omega_{3}$ is equal to $100 \mathrm{r} / \mathrm{min}, 300 \mathrm{r} / \mathrm{min}$, or $500 \mathrm{r} / \mathrm{min}$, both $T_{1}(t)$ and $T_{2}(t)$ quickly reach $80 \mathrm{~N}$ without overshoot or oscillation in the ADRC controller. In contrast, an increase in $\omega_{3}$ contributes to deterioration in the control abilities of $T_{1}(t)$ and $T_{2}(t)$ in the PID controller.

The simulation results show that once the ADRC controller is set up properly, it can handle a wide range of dynamic changes. Compared with the PID controller, Figures 5 and 6 


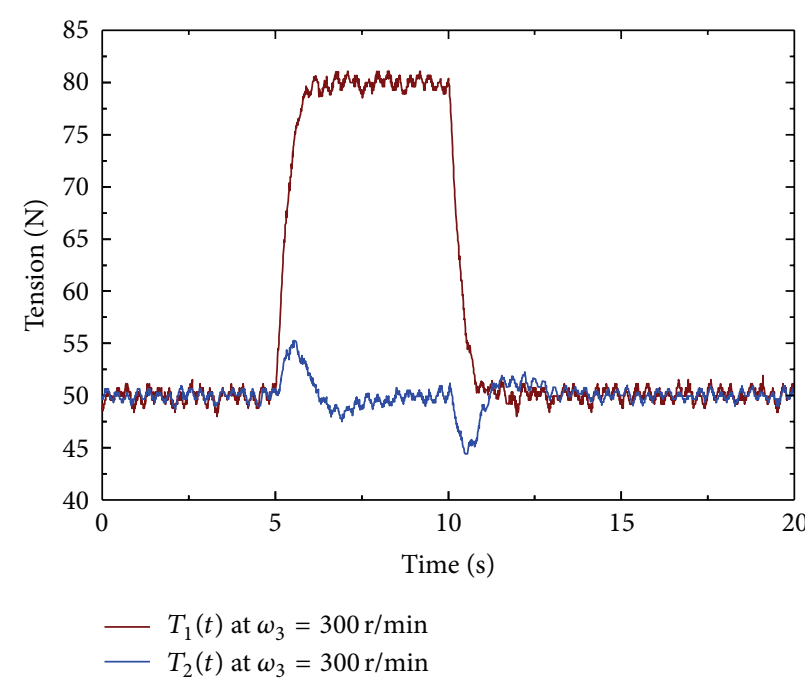

(a) Tension with PID controller

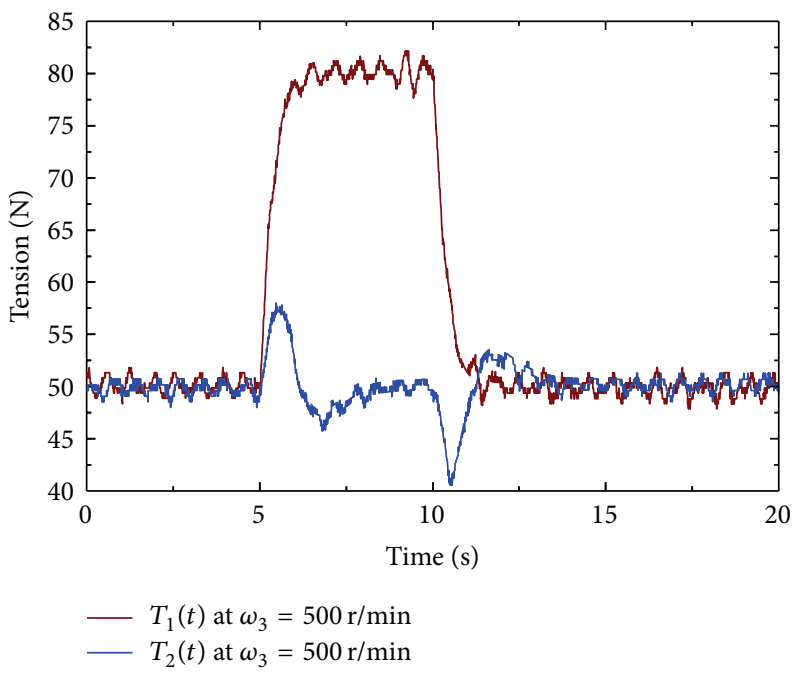

(c) Tension with PID controller

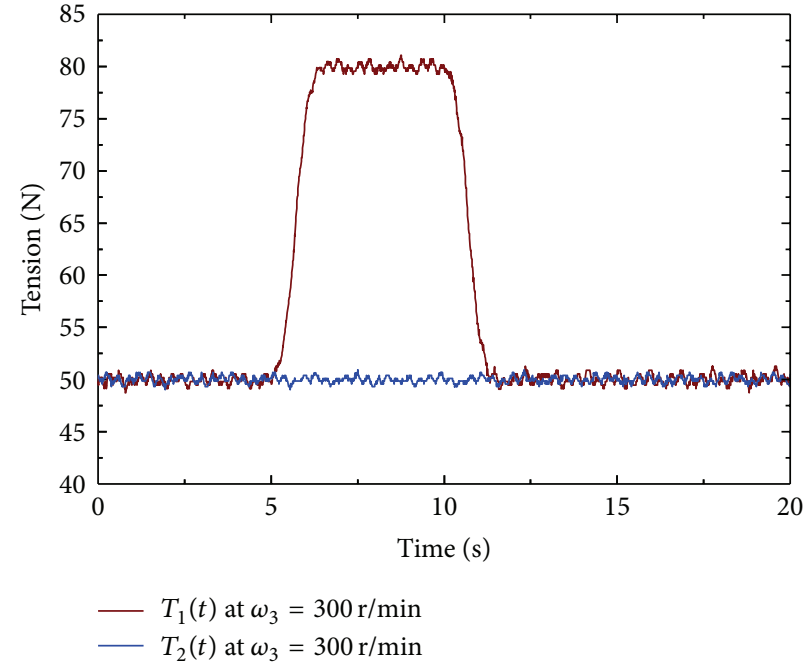

(b) Tension with ADRC controller

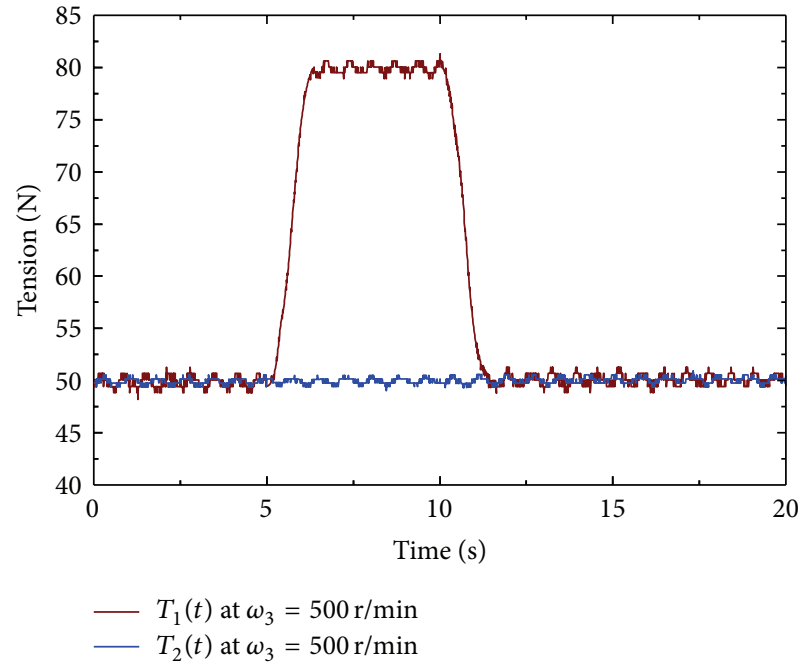

(d) Tension with ADRC controller

Figure 14: Decoupling response curves for $R_{1}=0.2 \mathrm{~m}$.

show that the ADRC controller can obtain better robustness against dynamic changes in the unwinding system. The primary reason is that uncertainties and variations in the internal model parameters can be actively estimated by the ESO and compensated by the NLSEF in the ADRC controller; the PID controller does not have these capabilities.

4.1.2. Case B: Decoupling Performance. To determine the decoupling performance of the proposed controller, the $T_{1}(t)$ step change is from $50 \mathrm{~N}$ to $80 \mathrm{~N}$ at $5 \mathrm{~s}$ and from $80 \mathrm{~N}$ to $50 \mathrm{~N}$ at $10 \mathrm{~s}$. Figures 7 and 8 illustrate the simulation performance of the PID and ADRC controllers when $\omega_{3}$ is equal to 100 $\mathrm{r} / \mathrm{min}$ and $R_{1}$ is equal to $0.2 \mathrm{~m}$, respectively.

Figure 7 indicates that when $R_{1}$ is equal to $0.2 \mathrm{~m}, 0.1 \mathrm{~m}$, or $0.05 \mathrm{~m}$, variations in $T_{1}(t)$ have no influence on $T_{2}(t)$ in the ADRC controller. In contrast, in the PID controller, $T_{2}(t)$ is continuously influenced by variations in $T_{1}(t)$, and variations in $T_{2}(t)$ increase with a decrease in $R_{1}$. As shown in Figure 8, when $\omega_{3}$ is equal to $100 \mathrm{r} / \mathrm{min}, 300 \mathrm{r} / \mathrm{min}$, or $500 \mathrm{r} / \mathrm{min}$, variations in $T_{1}(t)$ have no influence on $T_{2}(t)$ in the ADRC controller. However, in the PID controller, $T_{2}(t)$ is continuously influenced by variations in $T_{1}(t)$, and variations in $T_{2}(t)$ increase with an increase in $\omega_{3}$. For example, when $\omega_{3}$ is equal to $500 \mathrm{r} / \mathrm{min}$, variations in $T_{1}(t)$ at $5 \mathrm{~s}$ and $10 \mathrm{~s}$ cause $T_{2}(t)$ to vary by $6.5 \mathrm{~N}$.

The simulation results illustrate that the designed ADRC controller has better decoupling capability than the PID controller. Because the dynamic coupling components and the unknown coupled dynamics can be combined as the total disturbance estimated and compensated in real time, the decoupling control of the unwinding system in the ADRC controller can be realised, depending on the system order which can be easily obtained and the decoupling plant which may be inaccurate. However, the decoupling control cannot be realised, only depending on the imprecise of decoupling plant in the PID controller. 


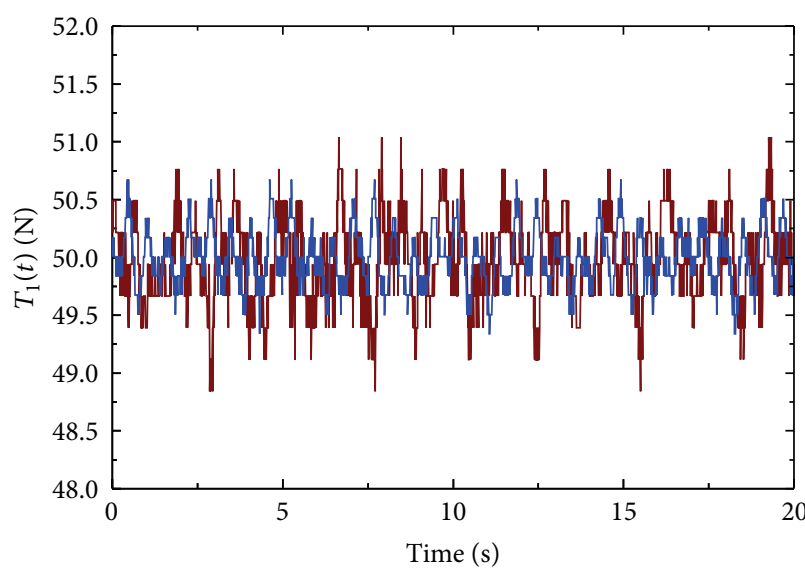

(a) $R_{1}=0.2 \mathrm{~m}$

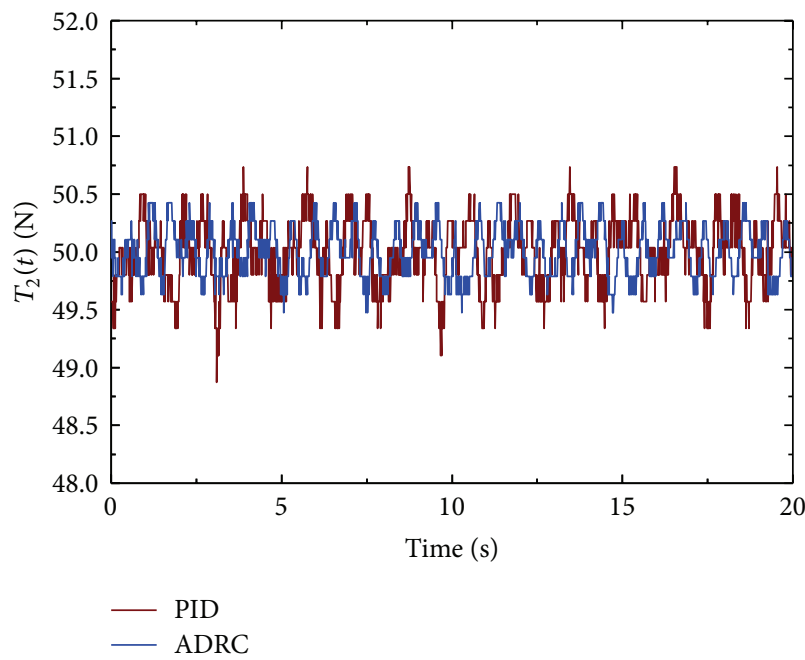

(c) $R_{1}=0.2 \mathrm{~m}$

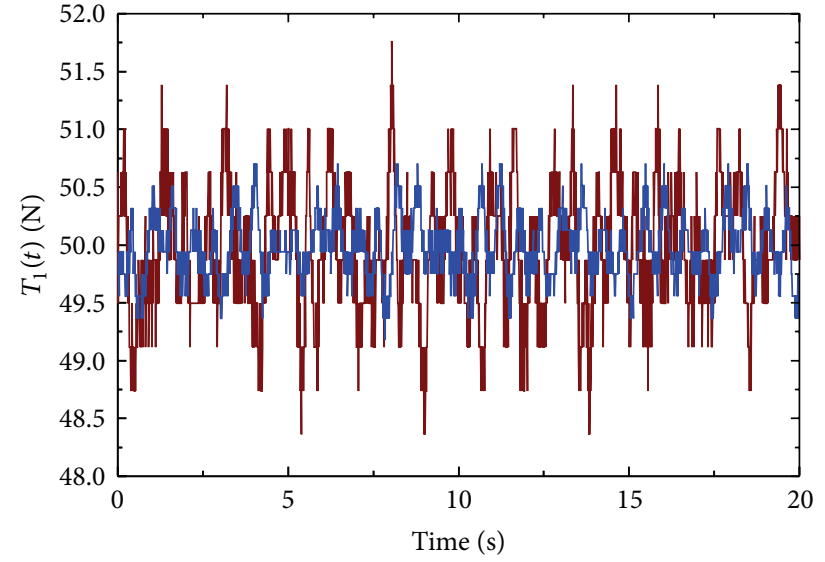

(b) $R_{1}=0.05 \mathrm{~m}$

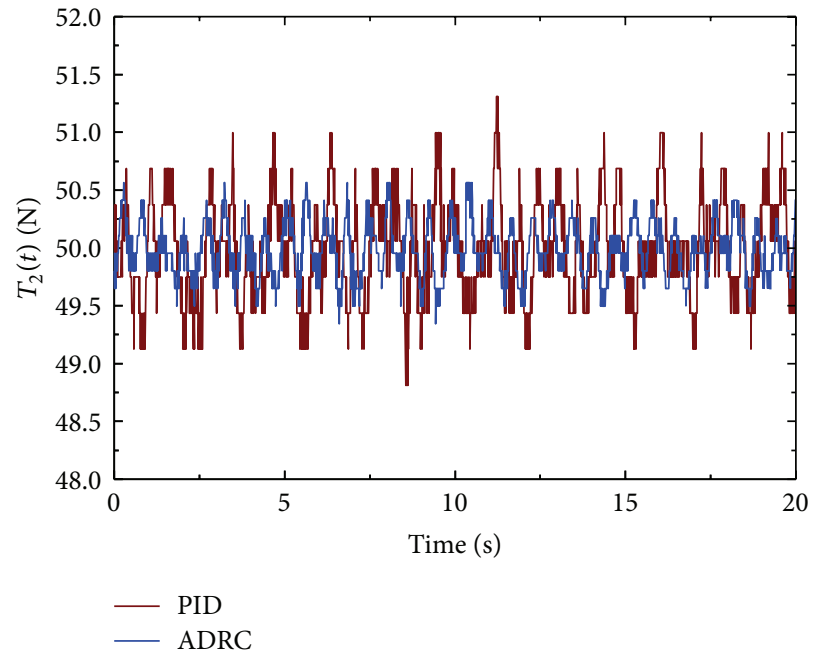

(d) $R_{1}=0.05 \mathrm{~m}$

Figure 15: Tension experimental curves for $\omega_{3}=100 \mathrm{r} / \mathrm{min}$.

4.1.3. Case C: External Antidisturbance Ability. To demonstrate the external antidisturbance ability of the proposed controller, a step disturbance of $T_{0}$ is set at $5 \mathrm{~s}$ with a value of $10 \mathrm{~N}$, and a step disturbance of $T_{1}(t)$ is set at $10 \mathrm{~s}$ with a value of $2 \mathrm{~N}$ when $\omega_{3}$ is equal to $100 \mathrm{r} / \mathrm{min}$ and $R_{1}$ is equal to $0.2 \mathrm{~m}$. The simulation behaviours of the PID and ADRC controllers are shown in Figures 9 and 10.

Figures 9 and 10 illustrate that with a decrease in $R_{1}$ and an increase in $\omega_{3}$, the web tension in the ADRC controller exhibits a trend similar to that of the PID controller, with a gradual increase in tension fluctuation. The range and duration of the tension fluctuation in the ADRC controller are much smaller than the range and duration of the tension fluctuation in the PID controller under similar simulation conditions. For example, when $R_{1}$ is equal to $0.05 \mathrm{~m}$, the range and duration of the fluctuation in $T_{1}(t)$ at $5 \mathrm{~s}$ are $0.5 \mathrm{~N}$ and $1.5 \mathrm{~s}$, respectively, in the ADRC controller. However, in the PID controller, the range and duration of the fluctuation in $T_{1}(t)$ at $5 \mathrm{~s}$ are $0.9 \mathrm{~N}$ and $4 \mathrm{~s}$, respectively. In the ADRC controller, when $\omega_{3}$ is equal to $500 \mathrm{r} / \mathrm{min}$, the range and duration of the fluctuation in $T_{1}(t)$ at $5 \mathrm{~s}$ are $0.8 \mathrm{~N}$ and $0.8 \mathrm{~s}$, respectively. However, the range and duration of the fluctuation in $T_{1}(t)$ under similar simulation conditions in the PID controller are $1.2 \mathrm{~N}$ and $2 \mathrm{~s}$, respectively.

The simulation results indicate that the proposed ADRC control methodology has a better external antidisturbance ability than the PID controller because the ADRC algorithm is less sensitive to disturbance.

4.2. Experimental Results. To establish practical application results of the ADRC control methodology, comparative experiments between the ADRC and PID control methodologies are performed in the experimental setup, as shown in Figure 1, with the servo cycle and sampling period set to $10 \mathrm{~ms}$ According to the parameters used in the simulation, the adjusted parameters of the PID and ADRC in experiments are presented in Table 3.

4.2.1. Case A: Robustness against Dynamic Changes. To determine the practical robustness against dynamic changes of the ADRC controller, the $T_{1}(t)$ and $T_{2}(t)$ step change is from $50 \mathrm{~N}$ 


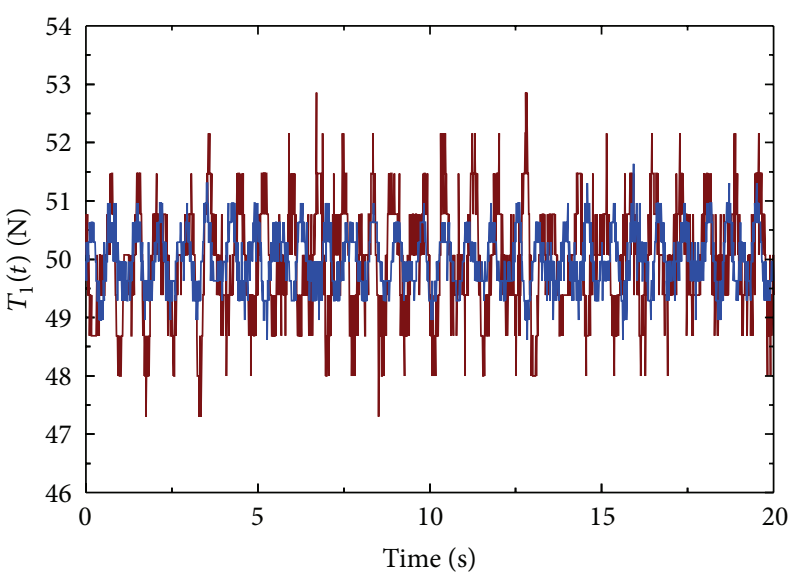

(a) $R_{1}=0.2 \mathrm{~m}$

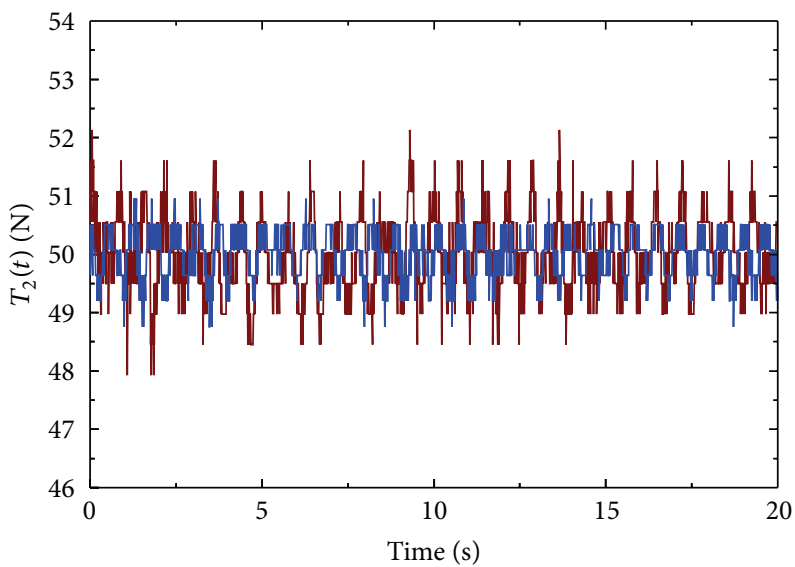

- PID

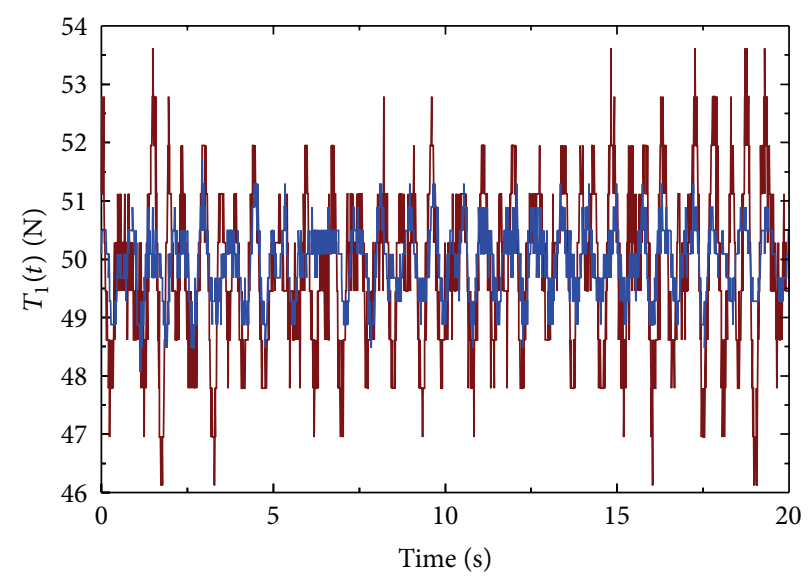

(b) $R_{1}=0.05 \mathrm{~m}$

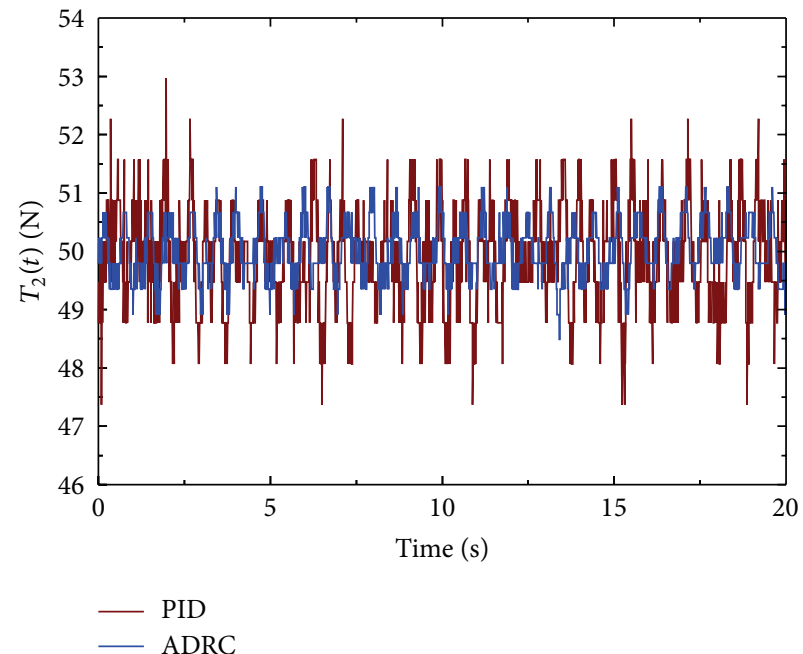

(d) $R_{1}=0.05 \mathrm{~m}$

(c) $R_{1}=0.2 \mathrm{~m}$

FIgURE 16: Tension experimental curves for $\omega_{3}=500 \mathrm{r} / \mathrm{min}$.

TABLE 3: Controller parameters in experiments.

\begin{tabular}{lc}
\hline Controller & Controller parameters \\
\hline ADRC1 & $\beta_{11}=100, \beta_{12}=6560, \beta_{13}=84700$, \\
$k_{1 p}=830, k_{1 d}=520, r_{1}=68$ \\
ADRC2 & $\beta_{21}=100, \beta_{22}=2950, \beta_{23}=54600$, \\
$k_{2 p}=2760, k_{2 d}=670, r_{2}=57$ \\
PID1 & $K_{1 p}=43, K_{1 i}=3.2, K_{1 d}=7$ \\
PID2 & $K_{2 p}=81, K_{2 i}=46, K_{2 d}=8$ \\
\hline
\end{tabular}

to $80 \mathrm{~N}$ at $5 \mathrm{~s}$ when $\omega_{3}$ is equal to $100 \mathrm{r} / \mathrm{min}$ and $R_{1}$ is equal to $0.2 \mathrm{~m}$. The performance of the PID and ADRC controllers in the experiments is shown in Figures 11 and 12.

Figures 11 and 12 show that with a decrease in $R_{1}$ and an increase in $\omega_{3}$, the control abilities of $T_{1}(t)$ and $T_{2}(t)$ deteriorate in the PID controller. However, when $\omega_{3}$ is equal to $100 \mathrm{r} / \mathrm{min}$ or when $R_{1}$ is equal to $0.2 \mathrm{~m}, T_{1}(t)$ and $T_{2}(t)$ quickly reach $80 \mathrm{~N}$ without overshoot in the ADRC controller. The experimental results are consistent with the simulation results and indicate that the proposed ADRC controller is superior to the PID controller in practical robustness against dynamic changes in the unwinding system. This finding is mainly due to the fact that uncertainties and variations in the internal model parameters can be actively estimated and compensated in the ADRC controller but are passively managed by parameters tuning in the PID controller.

4.2.2. Case B: Decoupling Performance. To establish the practical decoupling performance of the proposed controller, the $T_{1}(t)$ step change is from $50 \mathrm{~N}$ to $80 \mathrm{~N}$ at $5 \mathrm{~s}$ and from $80 \mathrm{~N}$ to $50 \mathrm{~N}$ at $10 \mathrm{~s}$ when $\omega_{3}$ is equal to $100 \mathrm{r} / \mathrm{min}$ and $R_{1}$ is equal to $0.2 \mathrm{~m}$. Figures 13 and 14 show the performance of the PID and ADRC controllers.

Figures 13 and 14 illustrate that $T_{2}(t)$ is always influenced by variation in $T_{1}(t)$ and the variation in $T_{2}(t)$ increases with a decrease in $R_{1}$ and an increase in $\omega_{3}$ in the PID controller. Unfortunately, when $\omega_{3}$ is equal to $100 \mathrm{r} / \mathrm{min}$ or $R_{1}$ is equal to $0.2 \mathrm{~m}$, the variation in $T_{1}(t)$ has no influence on $T_{2}(t)$ in the ADRC controller. The experimental results agree with 
TABLE 4: $S_{T 1}$ and $S_{T 2}$ in various test conditions.

\begin{tabular}{lcccc}
\hline \multicolumn{2}{c}{ Conditions } & \multicolumn{2}{c}{ Controller type } & \multicolumn{2}{c}{ ADRC controller } \\
& $S_{T 1}(\mathrm{~N})$ & $S_{T 2}(\mathrm{~N})$ & $S_{T 1}(\mathrm{~N})$ & $S_{T 2}(\mathrm{~N})$ \\
\hline$\omega_{3}=100 \mathrm{r} / \mathrm{min}, R_{1}=0.2 \mathrm{~m}$ & 0.3683 & 0.2949 & 0.2400 & 0.2163 \\
$\omega_{3}=100 \mathrm{r} / \mathrm{min}, R_{1}=0.05 \mathrm{~m}$ & 0.5540 & 0.4271 & 0.2686 & 0.2350 \\
$\omega_{3}=500 \mathrm{r} / \mathrm{min}, R_{1}=0.2 \mathrm{~m}$ & 0.9326 & 0.6572 & 0.4880 & 0.4064 \\
$\omega_{3}=500 \mathrm{r} / \mathrm{min}, R_{1}=0.05 \mathrm{~m}$ & 1.3349 & 0.8514 & 0.5831 & 0.4658 \\
\hline
\end{tabular}

the simulation results and illustrate that the designed ADRC controller has better decoupling capability than the PID controller. Because the dynamic coupling components and the unknown coupled dynamics can be combined as the total disturbance, which is estimated and compensated in real time, the decoupling control of the unwinding system can be realised, depending on the system order and the decoupling plant in ADRC controller. However, only depending on the decoupling plant, the decoupling control cannot be realised in the PID controller.

4.2.3. Case C: Tension Control Ability of Steady Speeds. Because tension control at steady speeds is essential for the performance of the gravure machine, further attention should be paid to tension fluctuation at steady speeds. To investigate the steady performance of the ADRC controller, tension control experiments were performed at motor steady speeds of $\omega_{3}=$ $100 \mathrm{r} / \mathrm{min}$ and $\omega_{3}=500 \mathrm{r} / \mathrm{min}$. In these experiments, the steady tension was $50 \mathrm{~N}$ and the test time was $20 \mathrm{~s}$. The performance of the PID and ADRC controllers in the experiments is shown in Figures 15 and 16. $S_{T 1}$ and $S_{T 2}$ are standard deviations of $T_{1}(t)$ and $T_{2}(t)$, respectively, and were obtained under different test conditions, just as shown in Table 4.

Figures 15 and 16 and Table 4 demonstrate that as the disturbance due to web speed and system dynamics increases, the web tension in the ADRC controller exhibits a trend similar to that of the PID controller, with a gradual increase in tension fluctuation. However, compared with the PID controller under similar experimental conditions, the resulting tension fluctuation in the ADRC controller is considerably smaller. For example, when $R_{1}$ is equal to $0.05 \mathrm{~m}$ and $\omega_{3}$ is equal to $500 \mathrm{r} / \mathrm{min}$, the standard deviations of $T_{1}(t)$ and $T_{2}(t)$ in the PID controller are $1.3349 \mathrm{~N}$ and $0.8514 \mathrm{~N}$, respectively. Under the ADRC controller, when $R_{1}$ is equal to $0.05 \mathrm{~m}$ and $\omega_{3}$ is equal to $500 \mathrm{r} / \mathrm{min}$, the standard deviations of $T_{1}(t)$ and $T_{2}(t)$ are $0.5831 \mathrm{~N}$ and $0.4658 \mathrm{~N}$, respectively. The experimental results indicate that the proposed ADRC controller has better tension control at steady speeds than the PID controller. The main reason is that the ADRC algorithm is much less sensitive to internal and external disturbances than the PID controller.

\section{Conclusions}

Based on ADRC, an innovative control synthesis methodology is proposed for the design of a tension decoupling controller for the unwinding system of the gravure printing machine. First, according to the working principle of the unwinding system, a nonlinear mathematical model is established. Second, a decoupling model is constructed to obtain the order and decoupling plant of the unwinding system, which establishes a basis for the ADRC decoupling control methodology. Last, the results of the simulation and experiments demonstrate that the proposed control methodology can achieve not only good decoupling control performance but also better stability and robustness than the traditional PID controllers. From this study, it can be found that in the ADRC framework, all of the unknown coupling terms that may contribute to the total disturbance can be actively estimated and cancelled out in the corresponding control signal in real time; this greatly simplifies the design of the decoupling control methodology.

The main contributions of this paper are as follows. (1) We have addressed the design of a tension decoupling controller based on ADRC for the unwinding system of gravure printing machines. (2) Simulation and experiments of the proposed decoupling controller for the unwinding system were completed. (3) The study demonstrates that the proposed method is a promising solution for the problem of tension control in the unwinding systems of gravure printing machines because it is inherently robust against internal and external disturbances and decoupling control over the unwinding system of the gravure printing machine can be achieved in a simple manner.

\section{Nomenclature}

$T_{0}$ : Constant tension of the unwinding roll $(\mathrm{N})$

$T_{i}: \quad$ Web tension in the $i$ th $\operatorname{span}(\mathrm{N})$

$w_{i}$ : External disturbances that influence $T_{i}$

$V_{i}$ : Tangential velocity of the $i$ th roll $(\mathrm{m} / \mathrm{s})$

$\omega_{i}$ : $\quad$ Rotational speed of the $i$ th roll $(\mathrm{r} / \mathrm{min})$

$u_{i}$ : Torque control signal of the $i$ th servo motor $(\mathrm{Nm})$

$L_{i}$ : Nominal span length of the web in the $i$ th $\operatorname{span}(\mathrm{m})$

$L_{D i}:$ The $i$ th arm length of the dancer roll (m)

$R_{i}$ : $\quad$ Radius of the $i$ th roll (m)

$J_{i}: \quad$ Inertia of the $i$ th roll $\left(\mathrm{kgm}^{2}\right)$

$J_{D a}:$ Inertia of the dancer roll $\left(\mathrm{kgm}^{2}\right)$

$C_{i}$ : Constant of the $i$ th servo motor

$T_{\text {iref }}$ : Reference inputs of $T_{i}(t)(\mathrm{N})$

$V_{\text {ref: }}$ : Reference inputs of $V_{3}(\mathrm{~m} / \mathrm{s})$ 
$K$ : Young's modulus of the spring $(\mathrm{N} / \mathrm{m})$

$A$ : Cross-sectional area of the web $\left(\mathrm{m}^{2}\right)$

$E$ : Modulus of elasticity of the web material $(\mathrm{Pa})$

$f: \quad$ Viscous friction coefficient $(\mathrm{Nm} /(\mathrm{rad} / \mathrm{s}))$

$f_{D}$ : Viscous friction coefficient of the dancer $\operatorname{roll}(\mathrm{Nm} /(\mathrm{rad} / \mathrm{s}))$

$\theta$ : Angle of the dancer roll arm from a neutral position ( $\mathrm{rad})$

$M_{i}$ : Servo motors driving the $i$ th roll.

\section{Conflict of Interests}

The authors declare that they have no financial or personal relationships with other people or organizations that can inappropriately influence their work; there is no professional or other personal interest of any nature or kind in any product or company that could be construed as influencing the position presented in, or the review of, the paper.

\section{Acknowledgments}

This research is supported by the Program for Changjiang Scholars (IRT1172) and the National Science and Technology Pillar Program of China, under Grant no. 2012BAF13B06.

\section{References}

[1] S. H. Jeon and J.-M. Kim, "Decoupling control of bridle rolls for steel mill drive system," IEEE Transactions on Industry Applications, vol. 35, no. 1, pp. 119-125, 1999.

[2] S.-H. Song and S.-K. Sul, "A new tension controller for continuous strip processing line," IEEE Transactions on Industry Applications, vol. 36, no. 2, pp. 633-639, 2000.

[3] K.-H. Shin, S.-O. Kwon, S.-H. Kim, and S.-H. Song, "Feedforward control of the lateral position of a moving web using system identification," IEEE Transactions on Industry Applications, vol. 40, no. 6, pp. 1637-1643, 2004.

[4] B.-J. Lee, S.-H. Kim, and C.-G. Kang, "Analysis of a nonlinear Web-tension control system of a high-speed gravure printing machine," in Proceedings of the SICE-ICASE International Joint Conference, pp. 893-898, Busan, Korea, October 2006.

[5] C. G. Kang and B. J. Lee, "MIMO tension modelling and control for roll-to-roll converting machines," in Proceedings of the 17th World Congress, International Federation of Automatic Control, pp. 11877-11882, Seoul, Korea, 2008.

[6] J. Li, X. Mei, T. Tao, and S. Liu, "Design tension controller of unwinding system based on BP neural network," Advanced Science Letters, vol. 4, no. 6-7, pp. 2222-2226, 2011.

[7] B.-M. Chung, S.-G. Lee, and C.-S. Cho, "Active tension control of high speed splitting machines using fuzzy PID," in Proceedings of the IEEE International Conference on Mechatronics (ICM '05), pp. 72-77, Taipei, Taiwan, July 2005.

[8] C. Wang, Y. Wang, R. Yang, and H. Lu, "Research on precision tension control system based on neural network," IEEE Transactions on Industrial Electronics, vol. 51, no. 2, pp. 381-386, 2004.

[9] N. R. Abjadi, J. Soltani, J. Askari, and G. R. Arab Markadeh, "Nonlinear sliding-mode control of a multi-motor web-wind- ing system without tension sensor," IET Control Theory and Applications, vol. 3, no. 4, pp. 419-427, 2009.

[10] P. R. Pagilla, N. B. Siraskar, and R. V. Dwivedula, "Decentralized control of web processing lines," in Proceedings of the IEEE International Conference on Control Applications, pp. 940-945, Toronto, Canada, 2005.

[11] P. R. Pagilla, N. B. Siraskar, and R. V. Dwivedula, "Decentralized control of web processing lines," IEEE Transactions on Control Systems Technology, vol. 15, no. 1, pp. 106-117, 2007.

[12] P. R. Pagilla, N. B. Siraskar, and R. V. Dwivedula, "A decentralized model reference adaptive controller for large-scale systems," in Proceedings of the 16th Triennial World Congress of International Federation of Automatic Control (IFAC '05), vol. 16, pp. 112-117, Prague, Czech republic, July 2005.

[13] H. Koç, D. Knittel, M. De Mathelin, and G. Abba, "Modeling and robust control of winding systems for elastic webs," IEEE Transactions on Control Systems Technology, vol. 10, no. 2, pp. 197-208, 2002.

[14] D. Knittel, E. Laroche, D. Gigan, and H. Koç, “Tension control for winding systems with two-degrees-of-freedom $\mathrm{H}_{\infty}$ controllers," IEEE Transactions on Industry Applications, vol. 39, no. 1, pp. 113-120, 2003.

[15] E. Laroche and D. Knittel, "An improved linear fractional model for robustness analysis of a winding system," Control Engineering Practice, vol. 13, no. 5, pp. 659-666, 2005.

[16] D. Knittel, D. Henrion, M. Vedrines, and P. Pagilla, "Fixed-order $\mathrm{H}_{\infty}$ decentralized control with model based feedforward for elastic web winding systems," in Proceedings of the IEEE Industry Applications Conference-Forty-First IAS Annual Meeting, vol. 3, pp. 1315-1322, Tampa, Fla, USA, October 2006.

[17] D. Knittel, M. Vedrines, D. Henrion, and P. Pagilla, "Robust $\mathrm{H}_{\infty}$ fixed order control strategies for large scale web winding systems," in Proceedings of the IEEE International Symposium on Intelligent Control, pp. 1964-1970, Munich, Germany, October 2006.

[18] D. Knittel, D. Henrion, M. Millstone, and M. Vedrines, "Fixedorder and structure $\mathrm{H}_{\infty}$ control with model based feedforward for elastic web winding systems," in Proceedings of the 11th IFAC/ IFORS/IMACS/IFIP Symposium on Large Scale Complex Systems Theory and Applications, vol. 11, pp. 131-136, Gdansk, Poland, 2007.

[19] A. Benlatreche, D. Knittel, and E. Ostertag, "Robust decentralised control strategies for large-scale Web handling systems," Control Engineering Practice, vol. 16, no. 6, pp. 736-750, 2008.

[20] V. Gassmann, D. Knittel, P. R. Pagilla, and M.-A. Bueno, "Fixedorder $\mathrm{H}_{\infty}$ tension control in the unwinding section of a web handling system using a pendulum dancer," IEEE Transactions on Control Systems Technology, vol. 20, no. 1, pp. 173-180, 2012.

[21] J. Han, "From PID to active disturbance rejection control," IEEE Transactions on Industrial Electronics, vol. 56, no. 3, pp. 900 906, 2009.

[22] J. Han, Active Disturbance Rejection Control Technique, National Defence Industry Press, Beijing, China, 2008.

[23] Z. Gao, Y. Huang, and J. Han, "An alternative paradigm for control system design," in Proceedings of the 40th IEEE Conference on Decision and Control (CDC' '01), vol. 5, pp. 4578-4585, Orlando, Fla, USA, December 2001.

[24] Z. Gao, "Active disturbance rejection control: a paradigm shift in feedback control system design," in Proceedings of the American Control Conference, pp. 2399-2405, Minneapolis, Minn, USA, June 2006. 
[25] Q. Zheng, L. Dong, D. H. Lee, and Z. Gao, "Active disturbance rejection control for MEMS gyroscopes," IEEE Transactions on Control Systems Technology, vol. 17, no. 6, pp. 1432-1438, 2009.

[26] F. J. Goforth and Z. Gao, "An active disturbance rejection control solution for hysteresis compensation," in Proceedings of the American Control Conference (ACC '08), pp. 2202-2208, Seattle, Wash, USA, June 2008.

[27] G. Tian and Z. Gao, "Benchmark tests of active disturbance rejection control on an industrial motion control platform," in Proceedings of the American Control Conference (ACC '09), pp. 5552-5557, St. Louis, Mo, USA, June 2009.

[28] J. Vincent, D. Morris, N. Usher et al., "On active disturbance rejection based control design for superconducting RF cavities," Nuclear Instruments and Methods in Physics Research A, vol. 643, no. 1, pp. 11-16, 2011.

[29] Y. Hou, Z. Gao, F. Jiang, and B. T. Boulter, "Active disturbance rejection control for web tension regulation," in Proceedings of the 40th IEEE Conference on Decision and Control (CDC'01), pp. 4974-4979, Orlando, Fla, USA, December 2001.

[30] W. Zhou and Z. Gao, "An active disturbance rejection approach to tension and velocity regulations in web processing lines," in Proceedings of the 16th IEEE International Conference on Control Applications, pp. 842-848, Singapore, October 2007.

[31] F. Mokhtari, P. Sicard, and A. Hazzab, "Decentralized nonlinear control strategies for disturbance rejection in winding systems," in Proceedings of the IEEE International Electric Machines and Drives Conference (IEMDC '11), pp. 230-235, Toronto, Canada, May 2011.

[32] S. Liu, X. Mei, F. Kong, and J. Shen, “Tension controller design for unwinding tension system based on active disturbance rejection control," in Proceedings of the IEEE International Conference on Mechatronics and Automation, pp. 1798-1803, Chengdu, China, 2012.

[33] K. H. Shin, Tension Control, TAPPI Press, 2000.

[34] C.-G. Kang and B.-J. Lee, "Stability analysis for design parameters of a roll-to-roll printing machine," in Proceedings of the International Conference on Control, Automation and Systems (ICCAS '07), pp. 1460-1465, Seoul, Korea, October 2007. 


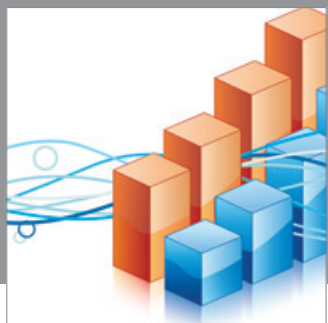

Advances in

Operations Research

mansans

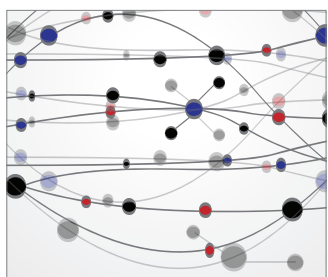

The Scientific World Journal
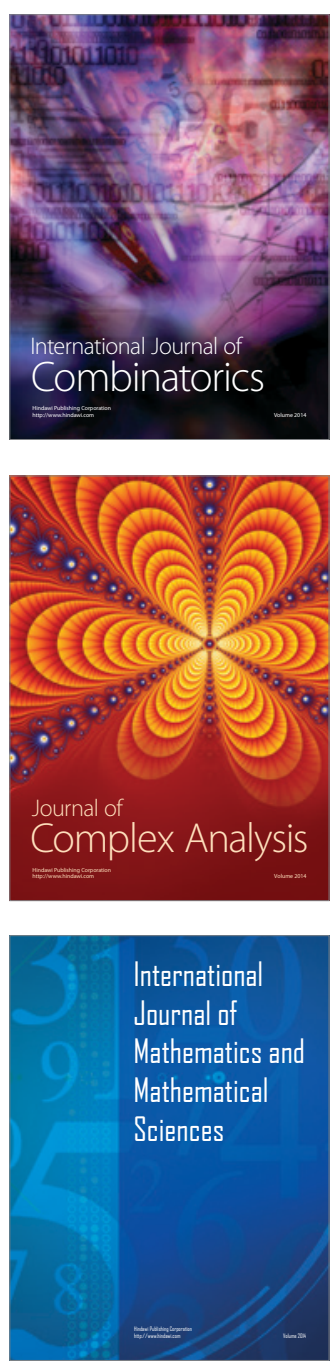
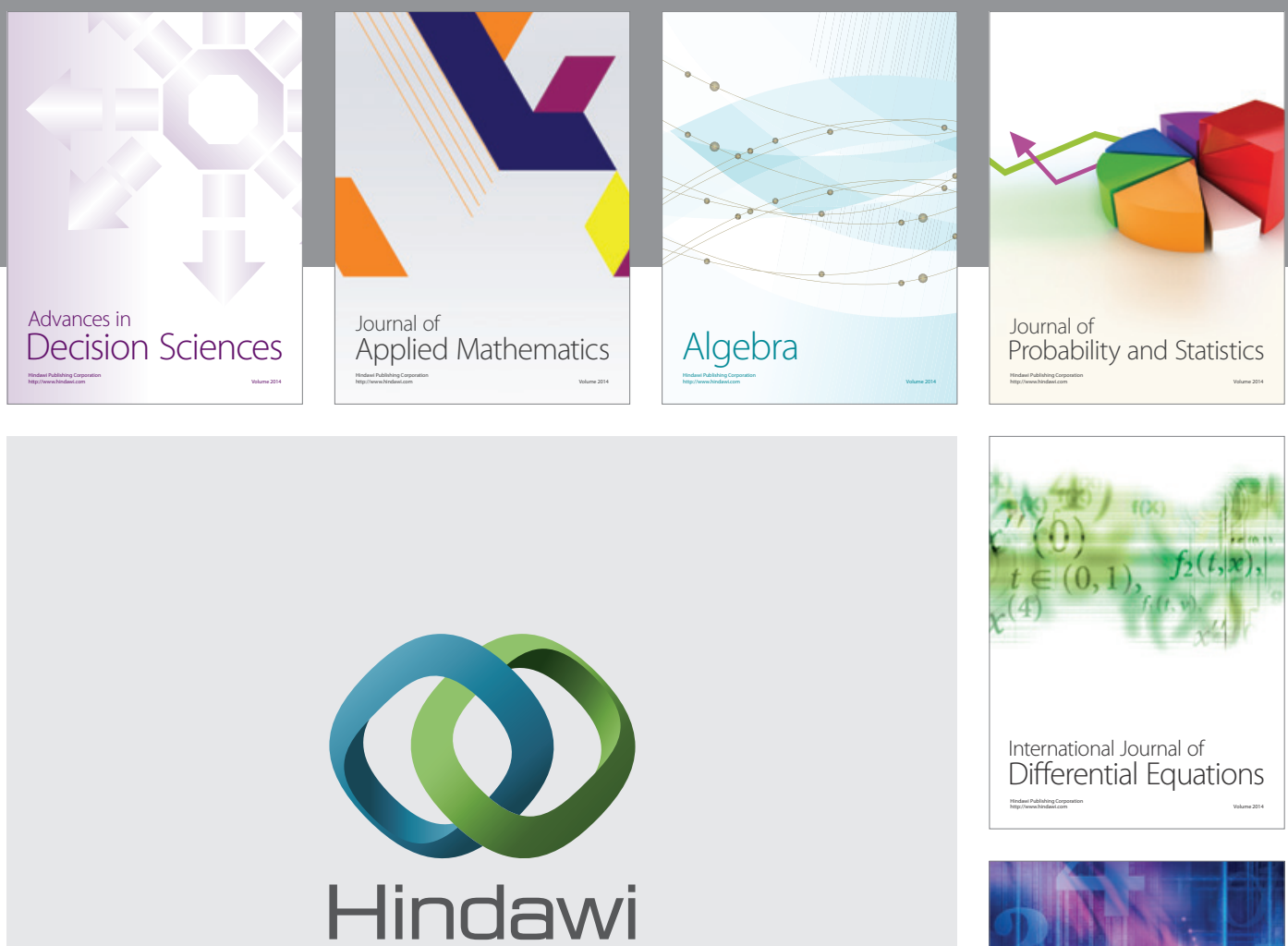

Submit your manuscripts at http://www.hindawi.com
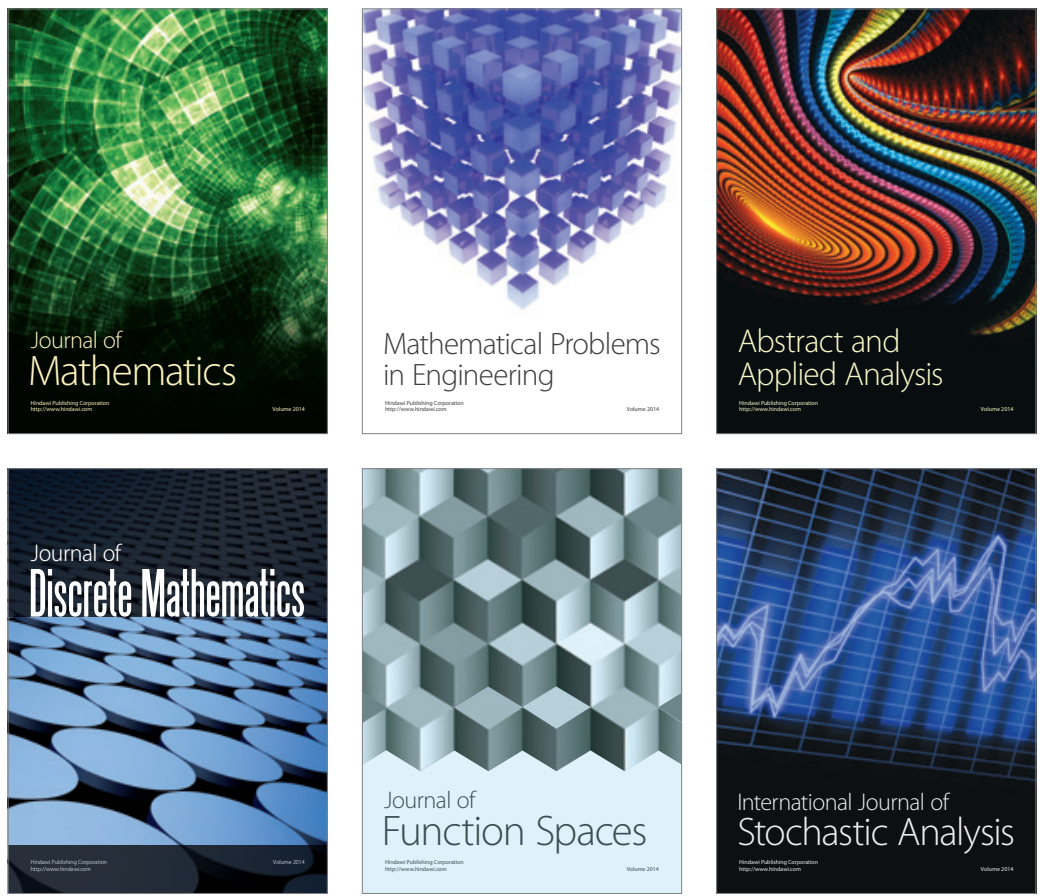

Journal of

Function Spaces

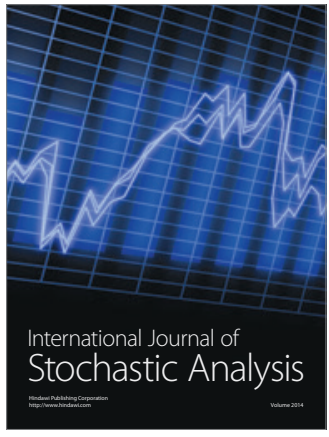

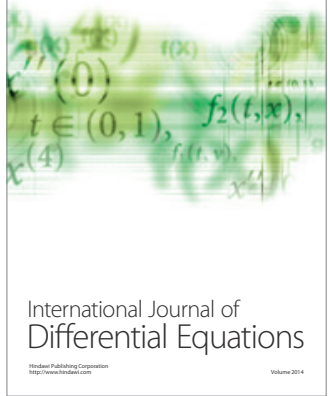
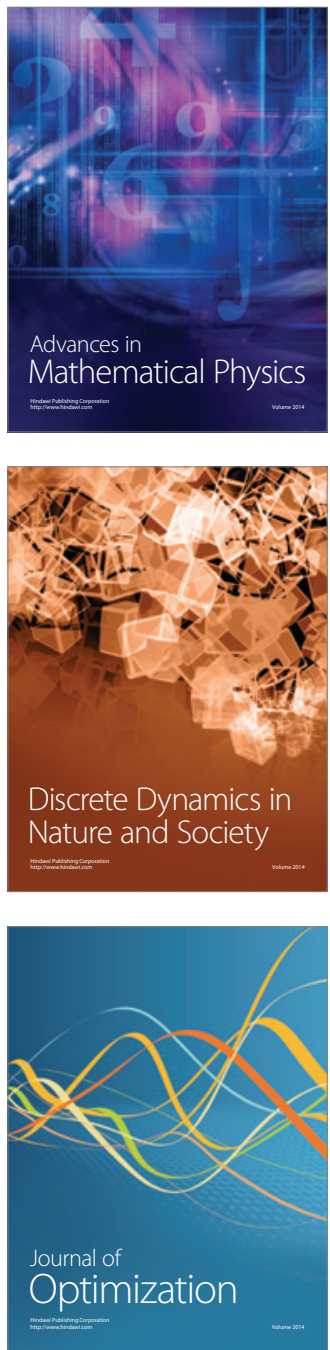